Article

\title{
Evaluation of a Microwave Emissivity Module for Snow Covered Area with CMEM in the ECMWF Integrated Forecasting System
}

\author{
Yoichi Hirahara ${ }^{1,2, *(\mathbb{D}}$, Patricia de Rosnay ${ }^{1}\left(\mathbb{D}\right.$ and Gabriele Arduini ${ }^{1}$ (D) \\ 1 European Centre for Medium-Range Weather Forecasts (ECMWF), Shinfield Park, Reading RG2 9AX, UK; \\ patricia.rosnay@ecmwf.int (P.d.R.); Gabriele.Arduini@ecmwf.int (G.A.) \\ 2 Japan Meteorological Agency (JMA), 1-3-4 Otemachi, Chiyoda-ku, Tokyo 100-8122, Japan \\ * Correspondence: hiraharayo@met.kishou.go.jp
}

Received: 5 July 2020; Accepted: 8 September 2020; Published: 11 September 2020

check for updates

\begin{abstract}
The Community Microwave Emission Modelling platform (CMEM) has been developed by the European Centre for Medium-Range Weather Forecasts (ECMWF) as the forward operator radiative transfer model for low frequency passive microwave brightness temperatures (TB). It is used at ECMWF for L-band TB monitoring over snow free areas. In this paper, upgrades to CMEM are presented in order to explore forward modelling in snow-covered areas for coupled land-atmosphere numerical weather prediction systems. The upgrades enable to use CMEM on an extended range of frequencies and the Helsinki University of Technology multi-layer snow emission model is implemented. Offline CMEM experiments are evaluated against AMSR2 (Advanced Microwave Scanning Radiometer 2) observations showing that simulated TB is improved when using a multi-layer snow scheme, compared to a single-layer scheme. The improvements mainly result from a better representation of snow characteristics in the multi-layer snowpack model. CMEM is also evaluated in the Integrated Forecasting System and coupled to RTTOV (Radiative Transfer for TOVS). The numerical results show improved simulated TB at low frequency $\mathrm{V}$ polarization over snow-covered area compared to a configuration using emissivity atlas. Degradations at frequencies higher than $20 \mathrm{GHz}$ indicate that further improvements are required in the emissivity and snowpack properties modelling.
\end{abstract}

Keywords: CMEM; IFS; RTTOV; HUT; H-TESSEL; multi-layer snowpack; AMSR2; emissivity

\section{Introduction}

The surface emissivity is critical for the assimilation of surface-sensitive satellite microwave data over land. Especially, in snow-covered regions, emissivity varies significantly with snow layer's properties [1]. At ECMWF (European Centre for Medium-Range Weather Forecasts), the microwave humidity and temperature-sounding channels are assimilated over land [2-5]. However, the assimilated channels are limited to those with small sensitivity to land surface, due to uncertainties in the emissivity and skin temperature. For the assimilated channels, retrieved emissivity [6] using observed brightness temperature at surface-sensitive channel is applied, backed-up by an emissivity atlas. In addition to retrieved emissivity and emissivity atlas, using a physical land emissivity model is an option to investigate for numerical weather prediction applications and coupled assimilation developments. Prigent et al. [7] evaluated the microwave land surface emissivity modeling of the Community Radiative Transfer Model (CRTM), providing quantitative statistic information for further model improvements and emphasized the needs for better physical modeling in arid regions and over snow-covered surfaces. 
CMEM (Community Microwave Emission Modelling platform) is the ECMWF radiative transfer model developed for low frequency passive microwave brightness temperature observation monitoring and data assimilation. It is currently used at ECMWF as the Soil Moisture and Ocean Salinity (SMOS) forward operator to simulate L-band brightness temperatures [8,9]. It accounts for state-of-the-art microwave emission parameterizations for low frequency passive microwave emission of soil and vegetation. It also includes the HUT (Helsinki University of Technology) single layer snow emission model [10]. However, as SMOS is used for soil moisture purpose at ECMWF, CMEM has been used on snow free areas only. CMEM uses input information from the ECMWF H-TESSEL (Hydrology-Tiled ECMWF Scheme for Surface Exchanges over Land) land surface model component of the ECMWF Integrated Forecasting System (IFS) [11,12]. H-TESSEL accounts for snow processes represented with a single-layer snow scheme currently used in operational weather forecasts at ECMWF [13]. A multi-layer snow model was recently developed in H-TESSEL [14]. Beside improving snow and low atmospheric level processes, it opens the possibility to explore multi-layer radiative transfer modelling and long-term perspectives of satellite radiances usage in coupled land-atmosphere assimilation system.

Based on the above, this paper investigates the usage of CMEM to estimate land surface emissivity over snow-covered areas and it explores combined snowpack and radiative transfer multi-layer approach. The performance of CMEM over snow-covered areas is evaluated at frequencies up to 18.7 GHz, using offline experiments for different CMEM configurations. In this case, CMEM is applied to generate brightness temperature from a range of model fields, including soil, vegetation and snow properties. Then, in order to explore the performances of CMEM for a larger range of microwave frequencies in an operational-like environment, coupled experiments are conducted in the full IFS system, with CMEM interfaced to the observation operator Radiative Transfer for TOVS (RTTOV $[15,16])$. In this configuration, RTTOV replaces the atmospheric module of CMEM and CMEM provides surface emissivity and effective temperature as input to RTTOV. The results are compared to simulated brightness temperatures using emissivity atlas TELSEM ${ }^{2}$ [17]. For these evaluations, we use observation data from the Advanced Microwave Scanning Radiometer 2 (AMSR2), which covers the $6.9 \mathrm{GHz}$ to $89 \mathrm{GHz}$ frequency range.

Section 2 presents the data and methods used in this paper. It presents CMEM and it describes its new developments and parameterisations. It also describes the configuration of the CMEM and experimental setup. Section 3 presents results of both the offline low frequencies and coupled all frequencies experiments. It includes discussions on the results. Section 4 concludes.

\section{Data And Methods}

\subsection{Gcom-W AMSR2 Brightness Temperature Observations}

The Japan Aerospace Exploration Agency (JAXA) is conducting the Global Change Observation Mission (GCOM) for continued long-term global meteorological and environmental monitoring [18]. The GCOM-W satellite is used for observations of the water cycle. It was launched on 18 May 2012. The Advanced Microwave Scanning Radiometer 2 (AMSR2) onboard the GCOM-W satellite is a remote sensing instrument for observations of microwave radiances from the Earth [19]. The AMSR2's antenna unit, which picks up microwave radiation from the Earth, rotates once every $1.5 \mathrm{~s}$, creating a conical scan pattern covering a width of about $1450 \mathrm{~km}$ on the Earth's surface. This scanning method can make one day and one night observation of more than $99 \%$ of the Earth's surface in two days. AMSR2 captures both horizontally and vertically polarized near-surface radiation in seven frequency bands, ranging from the $6.925 \mathrm{GHz}$ band to the $89.0 \mathrm{GHz}$ band (Table 1). The incidence angle is $55^{\circ}$ at the Earth's surface. In this paper, AMSR2 observations without bias correction are used to evaluate, over snow covered surfaces, the ECMWF brightness temperatures simulated using different parameterizations of radiative transfer models. AMSR2 observations are averaged (or superobbed) to about $80 \mathrm{~km} \times 80 \mathrm{~km}$ boxes in order to match the effective resolution of cloudy and precipitating 
systems in the ECMWF Integrated Forecasting System (IFS) [20]. Hereafter, the notations defined in Table 1 are used to specify AMSR2 channels.

Table 1. AMSR2 channels.

\begin{tabular}{lcccc}
\hline Band & Channel & Frequency (GHz) & Polarization & Notation \\
\hline $\mathrm{C}$ & 1,2 & 6.925 & $\mathrm{~V}, \mathrm{H}$ & $06 \mathrm{~V}, 06 \mathrm{H}$ \\
$\mathrm{C}$ & 3,4 & 7.3 & $\mathrm{~V}, \mathrm{H}$ & $07 \mathrm{~V}, 07 \mathrm{H}$ \\
$\mathrm{X}$ & 5,6 & 10.65 & $\mathrm{~V}, \mathrm{H}$ & $10 \mathrm{~V}, 10 \mathrm{H}$ \\
$\mathrm{Ku}$ & 7,8 & 18.7 & $\mathrm{~V}, \mathrm{H}$ & $19 \mathrm{~V}, 19 \mathrm{H}$ \\
$\mathrm{K}$ & 9,10 & 23.8 & $\mathrm{~V}, \mathrm{H}$ & $23 \mathrm{~V}, 23 \mathrm{H}$ \\
$\mathrm{Ka}$ & 11,12 & 36.5 & $\mathrm{~V}, \mathrm{H}$ & $37 \mathrm{~V}, 37 \mathrm{H}$ \\
$\mathrm{W}$ & 13,14 & 89.0 & $\mathrm{~V}, \mathrm{H}$ & $89 \mathrm{~V}, 89 \mathrm{H}$ \\
\hline
\end{tabular}

\subsection{Observation Operator Rttov}

In the IFS, the microwave radiance data from AMSR2 have been assimilated in all-sky conditions over ocean surfaces [21]. For the all-sky assimilation of microwave radiances inside the IFS, the observation operator Radiative Transfer for TOVS scattering, RTTOV-SCATT, [22] is used. RTTOV-SCATT is a component of the RTTOV package $[15,16]$, and it is an observation operator for microwave radiative transfer in cloudy, precipitating and clear skies. RTTOV simulates the top of atmosphere radiances in each of the channels of the sensor from atmospheric profile and surface variables. The surface emissivity can be either set as a prescribed input, or RTTOV can calculate it. For instance, in the IFS, the assimilation of SSMIS humidity-sounding channels in all-sky conditions over land relies on emissivity retrieved from satellite measurements at surface sensitive channels [4]. For the microwave humidity sounding channels (e.g., MHS, SSMIS), retrieved emissivity in a $90 \mathrm{GHz}$ channel is applied to the $183 \mathrm{GHz}$ channels [3,4]. In addition to this, for the microwave temperature sounding channels (e.g., AMSU-A, ATMS), retrieved emissivity in a $50.3 \mathrm{GHz}$ channel is applied to the 50-60 GHz channels in clear-sky assimilation [2,5]. If the emissivity retrieval fails or if it is too far from the climatology estimate, the emissivity retrieval is replaced by an atlas value. The Tool to Estimate Land Surface Emissivity from Microwave to Submillimeter Waves (TELSEM ${ }^{2}$ ) [17] is an emissivity data atlas for microwave sensors in RTTOV. It relies upon satellite-derived emissivities and is anchored to the SSM/I Tool to Estimate Land Surface Emissivities at Microwave Frequencies (TELSEM) [23] monthly climatology dataset. It includes emissivities information for snow and sea-ice. The frequency range is $10-700 \mathrm{GHz}$, therefore the emissivity at $10 \mathrm{GHz}$ is used for frequencies less than $10 \mathrm{GHz}$. In this paper we propose, in addition to the above approaches, to interface CMEM and RTTOV in the IFS. It allows using surface emissivity derived from land surface radiation model as CMEM as input of RTTOV, and conversely accounting for RTTOV atmospheric radiative transfer contribution in CMEM.

\subsection{Ecmwf Land Surface Model}

H-TESSEL (Hydrology-Tiled ECMWF Scheme for Surface Exchanges over Land) is the land surface model used in the ECMWF IFS [11,12]. In H-TESSEL, each soil column is discretized using 4 vertical layers, with no communication between horizontal grid cells. The depths of the soil layers are in an approximate geometric relation ( $7 \mathrm{~cm}$ for the top layer and then 21, 72, and $189 \mathrm{~cm}$ ). The soil surface can be covered by snow. The single-layer snow scheme currently used in operational weather forecasts at ECMWF and included in H-TESSEL (in IFS cycle 46R1) is an energy balance model describing the temporal evolution of the heat and mass contents of the snowpack [13]. In the IFS, a land surface data assimilation system is used to analyse the H-TESSEL snow and soil prognostic variables [24]. The snow analysis relies on a 2D Optimal Interpolation in which in situ snow depth and multi-sensor snow cover data are assimilated [25]. A multi-layer snow scheme was recently introduced in H-TESSEL to represent the vertical structure and evolution of snow temperature, density and liquid water content [14]. The number of active snow layers and their thicknesses are computed diagnostically 
at the beginning of each time step before the prognostic snowfields are updated. The number of active layers $(N)$ varies depending on the value of snow depth, from a minimum number of one layer, to a maximum of $N_{\max }=5$. The multi-layer snow scheme is being implemented and it is foreseen to be used for operational Numerical Weather Prediction (NWP) in the near future. H-TESSEL is fully coupled to the atmosphere for NWP applications and it has also been used in offline mode, forced by global reanalysis [11]. H-TESSEL land-use information is derived from the United States Geophysical Survey-Global Land Cover Classification (USGS-GLCC) [26] and the United Nations-Food and Agriculture Organization (UN-FAO) data set [27] interpolated to the same resolution as the forcing data. In H-TESSEL, snow water equivalent is arbitrarily set to $10^{4} \mathrm{~kg} \mathrm{~m}^{-2}$, for areas masked as glacier or ice shelves. These areas are not considered in this study. In this paper, H-TESSEL provides land surface conditions input to CMEM, including soil moisture and temperature, snow temperature, density, liquid water content and snow water equivalent.

\subsection{The Community Microwave Emission Modelling Platform}

CMEM has been developed by ECMWF as the forward operator for low frequency passive microwave brightness temperatures from 1 to $20 \mathrm{GHz}$ at the surface $[8,28-30]$. It is available with an Apache License Version 2.0 from the ECMWF CMEM webpage. CMEM is used by the scientific community for research and operational applications using low frequency passive microwave data [31-33]. As described in [8] CMEM is composed of four modules to compute the contributions from the soil, vegetation, snow and atmosphere to the Top-of-Atmosphere (TOA) brightness temperature; the modular structure allows the use of a range of parameterizations (Table 2). The default configuration used in this paper is highlighted in bold in the table. It is suitable to investigate modeling of emissions in snow covered areas. It differs from the default CMEM v6.1 release, which is used at ECMWF for SMOS applications over snow free areas. The latest version of CMEM (v6.1) is presented in this paper. It includes new options that make possible to account for multi-layer snowpack and simulate brightness temperature up to around $100 \mathrm{GHz}$. The following paragraphs describe updates from the previous version (v5.1) [8].

Table 2. Main modular configuration of CMEM. For each module components, a choice of parameterizations is available. Parameterizations in bold are the default used in this paper (setting for ML5 in Table 3). Italics indicate new models and parameterizations in CMEM v6.1.

\begin{tabular}{llc}
\hline CMEM Modules & \multicolumn{2}{c}{ Choice of Parameterizations } \\
& Short Name & Reference \\
\hline Soil module: & & \\
Dielectric mixing model & Dobson & {$[34]$} \\
& Mironov & {$[35]$} \\
& Wang & {$[36]$} \\
& Mironov 2009 & {$[37]$} \\
& Calvet & {$[38]$} \\
& Grody (desert only) & {$[39,40]$} \\
\hline Effective temperature model & Choudhury & {$[41]$} \\
& Holmes & {$[42]$} \\
& Surface temperature & \\
& Wigneron & {$[43]$} \\
\hline
\end{tabular}


Table 2. Cont.

\begin{tabular}{|c|c|c|}
\hline \multirow[t]{2}{*}{ CMEM Modules } & \multicolumn{2}{|l|}{ Choice of Parameterizations } \\
\hline & Short Name & Reference \\
\hline \multirow[t]{6}{*}{ Soil roughness model } & Wegmüller & [44] \\
\hline & Choudhury & [45] \\
\hline & Texture dependent & [46] \\
\hline & Wigneron 2001 & [43] \\
\hline & Wigneron 2007 & [47] \\
\hline & Wang & [48] \\
\hline \multicolumn{3}{|l|}{ Vegetation module: } \\
\hline \multirow[t]{4}{*}{ Vegetation optical depth model } & Wegmülller & [49] \\
\hline & Jackson & [50] \\
\hline & Kirdyashev & [51] \\
\hline & Wigneron & [47] \\
\hline \multirow[t]{3}{*}{ Vegetation temperature model } & Dual (Low Veg.: Tsurf, High Veg.: Tair) & \\
\hline & Surface temperature (Tsurf) & \\
\hline & Air temperature (Tair) & \\
\hline \multirow[t]{2}{*}{ Vegetation dielectric model } & Mätzler & [52] \\
\hline & Water & \\
\hline \multirow[t]{3}{*}{ Vegetation dielectric model (cold) } & Not frozen & \\
\hline & Ice & \\
\hline & Kou & [53] \\
\hline \multicolumn{3}{|l|}{ Snow module: } \\
\hline \multirow[t]{2}{*}{ Snow emission model } & HUT multi layer model & [54] \\
\hline & HUT single layer model & [10] \\
\hline \multirow[t]{3}{*}{ Snow volumetric moisture model } & Input (e.g., H-TESSEL) & \\
\hline & Anderson & {$[13,55]$} \\
\hline & Constant & \\
\hline \multirow{4}{*}{$\begin{array}{l}\text { Atmospheric module: } \\
\text { Atmospheric emission model }\end{array}$} & & \\
\hline & Pellarin & [56] \\
\hline & Ulaby & [57] \\
\hline & Input (e.g., RTTOV) & \\
\hline
\end{tabular}

\subsubsection{Cmem Soil Module}

In the soil module, the dielectric mixing model is used to compute the soil dielectric constant depending on the microwave frequency, soil moisture and temperature and soil texture. In order to simulate brightness temperature at a frequency higher than $20 \mathrm{GHz}$, the Calvet dielectric mixing model is added in CMEM v6.1 [38]. It relies on a calibration of the Wang and Schmugge empirical model [36] for high frequencies, using the Portos-93 field experiment [58] observations at 23.8, 36.5 and $90 \mathrm{GHz}$. Compared to previous versions of CMEM, the soil module of CMEM v6.1 was enhanced with the implementation of the Mironov dielectric mixing model accounting for temperature effects [37], the Wang soil roughness model for C-band [48], and the Grody and Weng desert emissivity parameterization $[39,40]$.

\subsubsection{Cmem Vegetation Module}

In the vegetation module of CMEM, vegetation attenuates the surface emission, and it acts as a source of emission itself. The brightness temperature $T_{\mathrm{Bveg}(p, \theta)}$ is expressed as

$$
T_{\mathrm{Bveg}(p, \theta)}=T_{\mathrm{C}}\left(1-\omega_{(p, \theta)}\right)\left(1-\exp \left(-\tau_{\mathrm{veg}(p, \theta)}\right)\right)
$$

where $T_{\mathrm{C}}$ is the canopy temperature, $\omega_{(p, \theta)}$ is the single scattering albedo and $\tau_{\operatorname{Bveg}(p, \theta)}$ is the vegetation optical depth for polarization $p$ and frequency $\theta$. While the vegetation optical depth model 
Wigneron [47] and Jackson [50] are most suitable at L-band, the Kirdyashev [51] and Wegmüller [49] models account for the wave number in their parameterization. Especially, the Wegmüller model is applicable to a larger range of frequencies (1-100 GHz). While Jackson and Wigneron models rely on empirical parameters, LAI and vegetation water content (Jackson), Kirdyashev and Wegmüller models consider the dielectric constant of vegetation in their parameterizations accounting for dielectric constant of liquid water and ice. In CMEM v6.1, vegetation dielectric computation is introduced as an explicit new component of the vegetation module for Kirdyashev and Wegmüller models (Table 2). The Mätzler model [52] is valid for non-frozen vegetation and it is now part of the CMEM choice of parameterizations. It is applicable to 1-100 GHz. For cold vegetation, the Kou [53] empirical model for the distribution of water and ice for vegetation in frozen environments is applicable. A non-frozen water dielectric model is also included in CMEM's vegetation module. It assumes liquid water exists at $0{ }^{\circ} \mathrm{C}$ in the vegetation, with Mätzler model's applied, when the canopy temperature is below $0{ }^{\circ} \mathrm{C}$.

The CMEM vegetation module takes the subgrid-scale variability of the land surface into account. Up to seven tiles can be considered in each CMEM grid box: bare soil, low vegetation, high vegetation (each are either free of snow or snow covered), and open water. When snow is present, a snow layer is added on the top of bare soil or low vegetation tiles, and high vegetation is treated as covering the snow surface. Distinct canopy temperatures for low and high vegetation are accounted for in CMEM v6.1. If the Dual vegetation temperature parameterization (Table 2) is selected, soil top layer temperature and air temperature at $2 \mathrm{~m}$ are used as an approximation for low and high vegetation canopy temperature, respectively. For parameterization other than vegetation temperature (optical depth model, dielectric model), the same parameterization is set to high and low vegetation.

\subsubsection{Cmem Snow Module}

CMEM accounts for snow when present, using the Helsinki University of Technology (HUT) model to compute the snowpack reflectivity [10]. In order to simulate the vertically structured natural snowpack, the multi-layer HUT model [54] is implemented in CMEM v6.1. If only one snow layer is present, the model reverts to the single-layer version. In HUT, snow is characterized by temperature, moisture, density, thickness, salinity and grain size. The model snow grain size is represented in CMEM following $[55,59]$. It is expressed as a function of snow density as

$$
d=\min \left\{a+b \rho^{4}, d_{\max }\right\}
$$

where $d$ represents effective grain size in $\mathrm{m}, a=1.6 \times 10^{-4}, b=1.1 \times 10^{-13}, \rho$ is the snow density in $\mathrm{kg} \mathrm{m}^{-3}$ and $d_{\max }=3.0 \times 10^{-3} \mathrm{~m}$.

In contrast to previous versions of CMEM, which used a constant value, snow volumetric moisture variability in the snowpack, is accounted for in CMEM v6.1. It is computed as

$$
M_{\mathrm{v}}=V_{\mathrm{w}} / V_{\mathrm{s}}=\left(w_{\mathrm{slw}} / \rho_{\mathrm{w}}\right) /\left(w_{\mathrm{swe}} / \rho_{\mathrm{s}}\right)
$$

where $M_{\mathrm{v}}$ represents volumetric moisture, $V_{\mathrm{w}}\left(\mathrm{m}^{3}\right)$ is the volume of water in snow, $V_{\mathrm{s}}\left(\mathrm{m}^{3}\right)$ is the total volume of snow (ice + water + air), $w_{\text {slw }}\left(\mathrm{kg} \mathrm{m}^{-2}\right)$ is the snow liquid water content, $w_{\text {swe }}\left(\mathrm{kg} \mathrm{m}^{-2}\right)$ is the snow water equivalent, $\rho_{\mathrm{W}}\left(\mathrm{kg} \mathrm{m}^{-3}\right)$ is the density of water and $\rho_{\mathrm{s}}\left(\mathrm{kg} \mathrm{m}^{-3}\right)$ is the density of snow. When the snow volumetric moisture model is input, $M_{\mathrm{V}}$ is calculated from Equation (3). When the snow volumetric moisture model is Anderson model, $w_{\text {slw }}$ is provided from input parameter or computed diagnostically following $[13,55]$ as

$$
w_{\mathrm{slw}}=f\left(T_{\mathrm{sn}}\right) S_{\mathrm{c}}
$$

where $f\left(T_{\mathrm{sn}}\right)$ is a snow temperature $T_{\mathrm{sn}}(\mathrm{K})$ function and $S_{\mathrm{c}}\left(\mathrm{kg} \mathrm{m}^{-2}\right)$ is the snow liquid water capacity. If multi-layer HUT $\left(N_{\max }>1\right)$ is selected, snow temperature, density, snow water equivalent and snow liquid water content for each snow layer are needed as input parameter for HUT. 


\subsubsection{Cmem Atmospheric Module}

For polarization $p$ and incidence angle $\theta$, CMEM computes the Top-of-Atmosphere (TOA) brightness temperature $T_{\mathrm{Btoa}(p, \theta)}$ at each model grid point as

$$
\begin{aligned}
T_{\mathrm{Btoa}(p, \theta)}= & T_{\mathrm{Batm}(p, \theta)}^{\uparrow}+T_{\mathrm{Btov}(p, \theta)} \exp \left(-\tau_{\mathrm{atm}(p, \theta)}\right) \\
T_{\mathrm{Btov}(p, \theta)}= & T_{\mathrm{Bsoil}(p, \theta)} \exp \left(-\tau_{\operatorname{veg}(p, \theta)}\right) \\
& +T_{\mathrm{Bveg}(p, \theta)}\left[1+r_{(p, \theta)} \exp \left(-\tau_{\operatorname{veg}(p, \theta)}\right)\right] \\
& +T_{\operatorname{Batm}(p, \theta)}^{\downarrow} r_{(p, \theta)} \exp \left(-2 \tau_{\operatorname{veg}(p, \theta)}\right)
\end{aligned}
$$

where $T_{\operatorname{Batm}(p, \theta)}^{\uparrow}$ is the upwelling atmospheric emission, $\tau_{\operatorname{atm}(p, \theta)}$ is the atmospheric optical depth and $T_{\operatorname{Btov}(p, \theta)}$ is the brightness temperature at the top of the vegetation layer. $T_{\mathrm{Bsoil}(p, \theta)}, T_{\mathrm{Bveg}(p, \theta)}$ and $T_{\mathrm{Batm}(p, \theta)}^{\downarrow}$ are the brightness temperature of soil, vegetation layer, and downward atmospheric emission, respectively. $r_{(p, \theta)}$ is the rough soil surface reflectivity and $\tau_{\mathrm{veg}(p, \theta)}$ is the vegetation optical depth. In the atmospheric module of CMEM, $\tau_{\operatorname{atm}(p, \theta)}, T_{\operatorname{Batm}(p, \theta)}^{\uparrow}$ and $T_{\text {Batm }(p, \theta)}^{\downarrow}$ are computed by a simple parameterization, the so-called Pellarin model [56]. The Pellarin model mainly accounts for surface altitude and air temperature at $2 \mathrm{~m}$, therefore it is suitable for low frequency where the influence of water vapor in the atmosphere is small. The Ulaby model [57] takes into account water vapor density near the surface; however, it is applicable only to specific frequencies.

\subsubsection{Cmem-Rttov Interface in The Ifs}

As seen from Section 2.5.2 CMEM v6.1 is able to interface to RTTOV (Section 2.2) in the IFS, so that the coupled CMEM-RTTOV can be used as an optional forward model for NWP developments. CMEM-RTTOV allows accounting for the full atmospheric vertical profile and to simulate brightness temperature at a frequency higher than $20 \mathrm{GHz}$. In this configuration, RTTOV replaces the atmospheric module of CMEM and in turn CMEM provides effective surface emissivity and temperature as input to RTTOV.

In the case of a non-scattering plane parallel atmosphere, for polarization $p$ and incidence angle $\theta$, the brightness temperature as observed by a satellite sensor $T_{\operatorname{Btoa}(p, \theta)}$ can be expressed in the model space following [6] as;

$$
T_{\text {Btoa }(p, \theta)}=\varepsilon_{(p, \theta)} T_{\text {phys }} \exp \left(-\tau_{\text {atm }(p, \theta)}\right)+\left(1-\varepsilon_{(p, \theta)}\right) T_{\text {Batm }(p, \theta)}^{\downarrow} \exp \left(-\tau_{\text {atm }(p, \theta)}\right)+T_{\text {Batm }(p, \theta)}^{\uparrow}
$$

where $T_{\text {phys }}, T_{(p, \theta)}^{\downarrow}$ and $T_{(p, \theta)}^{\uparrow}$ are the physical temperature at the surface, the atmospheric downwelling and upwelling brightness temperature, respectively. $\varepsilon_{(p, \theta)}$ is the surface emissivity corresponding to $T_{\text {phys }}, \exp \left(-\tau_{\operatorname{atm}(p, \theta)}\right)$ is the net atmospheric transmissivity. From Equation (5) and $(7), \varepsilon_{(p, \theta)}$ can be expressed as;

$$
\varepsilon_{(p, \theta)}=\left(T_{\operatorname{Btov}(p, \theta)}-T_{\operatorname{Batm}(p, \theta)}^{\downarrow}\right) /\left(T_{\text {phys }}-T_{\text {Batm }(p, \theta)}^{\downarrow}\right)
$$

$T_{\operatorname{Btov}(p, \theta)}$ is computed from Equation (6) and $T_{\text {Batm }(p, \theta)}^{\downarrow}$ can be given from an external radiation model as a first guess. From Equation $(8), \varepsilon_{(p, \theta)}$ is derived as the effective emissivity corresponding to $T_{\text {phys }}$. $T_{\text {phys }}$ is set to the skin or effective temperature used in the CMEM soil module. CMEM v6.1 can output the set of $\varepsilon_{(p, \theta)}$ and $T_{\text {phys }}$ for external radiation models.

\subsection{Numerical Experiments}

This study is based on results of offline and coupled numerical experiments. In the offline experiments, CMEM is used as a standalone model that input data provided by H-TESSEL land surface simulations forced by ERA5 [60] atmospheric conditions. The offline experiments are used to explore and to evaluate the new parameterizations implemented in CMEM v6.1. They are cost-effective, 
therefore suitable for evaluation of several configurations for long-term experiments. The coupled experiments are conducted in the full IFS system, using CMEM-RTTOV. They aim at exploring CMEM-RTTOV performance over snow covered surface in an operational-like environment for a larger range of microwave frequencies than offline experiments.

\subsubsection{Offline Experiments}

Table 3 summarizes the offline experiments conducted in this paper. They are conducted at the three lowest AMSR2 bands (C-band, X-band and Ku-band), which are compatible with the CMEM atmospheric module. In order to evaluate the effect of multi-layer snow, three configurations of CMEM H-TESSEL experiments are conducted:

Table 3. Offline CMEM H-TESSEL experiments acronyms and settings. All the experiments use CMEM v6.1 in its default version shown in Table 2, with different snow configurations and different approaches to represent vegetation in CMEM. They are conducted at AMSR2 C-band, X-band and Ku-band at vertical (V) and horizontal (H) polarizations, from 01 October 2017 to 30 Jun 2018.

\begin{tabular}{lll}
\hline Exp Name & H-TESSEL Snow Model & CMEM Specificity \\
\hline ML5 & multi-layer snow $\left(N_{\max }=5\right)$ & Default (Table 2) \\
SL1 & single-layer snow & ML5 but Snow volumetric moisture model is Anderson \\
ML1 & multi-layer snow aggregated to single-layer & ML5 but Snow volumetric moisture model is Anderson \\
\hline TSO & multi-layer snow $\left(N_{\max }=5\right)$ & ML5 but Vegetation temperature model is Tsoil \\
ICE & multi-layer snow $\left(N_{\max }=5\right)$ & ML5 but Vegetation dielectric model (cold) is Ice \\
KOU & multi-layer snow $\left(N_{\max }=5\right)$ & ML5 but Vegetation dielectric model (cold) is Kou \\
NOH & multi-layer snow $\left(N_{\max }=5\right)$ & ML5 but Fraction of high vegetation is setted to 0 \\
\hline
\end{tabular}

- ML5: inputs H-TESSEL results created by the multi-layer snow scheme up to 5 layers.

- SL1: inputs H-TESSEL results created by the single-layer snow scheme.

- ML1: inputs H-TESSEL results created by the multi-layer snow scheme up to 5 layers. The multi-layer snow fields are aggregated in a single-layer to represent the bulk properties of the snowpack [14]. Regarding the temperature, this is the temperature corresponding to the total heat (cold) content of the snowpack.

They all use CMEM with its default settings (Table 2) except for the snow volumetric moisture model. This is because the snow liquid water content is output only by the H-TESSEL experiment using the multi-layer snow scheme, therefore ML5 uses as input the snow liquid water content to compute the volumetric snow moisture from Equation (3), whereas SL1 and ML1 use the Anderson model to compute the volumetric snow moisture (Equations (3) and (4)).

In ML5, the air temperature at $2 \mathrm{~m}$ is used as an approximation for high vegetation (covering the snow surface) canopy temperature and water in the vegetation is treated as non-freezing because of the cold resistance of the vegetation. In addition to the above, for the purpose of evaluating the effect of vegetation over snow, four multi-layer snow experiments are conducted (Table 3):

- $\quad$ TSO: soil temperature at the top layer is used as an approximation for high vegetation (covering the snow surface) canopy temperature similarly to the default setting of CMEM v5.1.

- ICE: dielectric constant of ice is used for cold vegetation similarly to the default setting of CMEM v5.1.

- KOU: Kou model about dielectric constant of vegetation is used for cold vegetation.

- $\mathrm{NOH}$ : simulations assume that there is no vegetation on the snow.

They are consistent with ML5 in terms of volumetric snow moisture representation and the number of snowpack layers.

For all the seven offline CMEM experiments, CMEM input data are soil moisture, soil temperature, snow depth, snow density, snow liquid water content and snow temperature provided by H-TESSEL land surface simulations forced by ERA5 atmospheric conditions. These H-TESSEL simulations cover 
the time period from June 2010 to June 2018 to reduce spin up issues. CMEM also uses the air temperature at $2 \mathrm{~m}$ from ERA5. Experiments are conducted at a horizontal resolution of approximately $30 \mathrm{~km}$ (Tco399, spectral triangular truncation 399 with a cubic grid). For comparison, observation data are assigned to the nearest grid point. CMEM offline experiments span a 9-month period covering the boreal winter, from 01 October 2017 to 30 June 2018, with output every 6 h at 00 UTC, 06 UTC, 12 UTC and $18 \mathrm{UTC}$, using a time window covering $\pm 3 \mathrm{~h}$.

\subsubsection{Coupled Experiments with Cmem-Rttov in the IFS}

Table 4 describes the experiments conducted for this study using coupled CMEM-RTTOV radiative transfer models in the IFS. They are based on IFS cycle 46R1 with RTTOV version 12.2. In IFS:ATLAS, RTTOV simulates brightness temperature with emissivity obtained from the TELSEM ${ }^{2}$. In IFS:CMEM, RTTOV coupled with CMEM as seen Section 2.4.5 simulates brightness temperature. Both experiments are initialized every time with the ECMWF operational analysis data. The monitoring experiments compute Top-of-Atmosphere AMSR2 first guess departures (observation minus model first guess).

Table 5 describes the configuration of CMEM in IFS:CMEM. In the IFS cycle 46R1, a single-layer snow scheme is used in H-TESSEL, therefore the maximum number of snow layers about multi-layer HUT model $N_{\max }=1$. The snow liquid water content is not a prognostic variable in the single-layer snow scheme used in H-TESSEL, hence the Andeson model is used to diagnose the snow volumetric moisture. Considering the applicable frequency bands, the Dobson dielectric mixing model is used at frequencies below $20 \mathrm{GHz}$ and the Calvet model is used at frequencies above $20 \mathrm{GHz}$. Other settings are the same as the default in Table 2.

Table 4. Coupled CMEM-RTTOV monitoring experiments in the IFS. All the experiments use IFS cycle 46r1, with RTTOV version 12.2. They are conducted at AMSR2 C-band, X-band, Ku-band, K-band, Ka-band and W-band (Table 1), at vertical (V) and horizontal (H) polarizations, from 01 January 2019 to 31 January 2019.

\begin{tabular}{ll}
\hline Exp Name & Snow Surface Emissivity \\
\hline IFS:ATLAS & TELSEM $^{2}$ [17] \\
IFS:CMEM & CMEM v6.1 $^{\text {CMEM }}$ \\
\hline
\end{tabular}

Table 5. Modular configuration of IFS:CMEM in Table 4.

\begin{tabular}{ll}
\hline CMEM Modules & Choice of Parameterizations \\
\hline Soil Dielectric mixing model & Dobson $(\leq 20 \mathrm{GHz})$, Calvet $(>20 \mathrm{GHz})$ \\
Soil Effective temperature model & Choudhury \\
Soil roughness model & Wegmüller \\
\hline Vegetation optical depth model & Wegmüller \\
Vegetation temperature model & Dual(Low Veg.: Tsurf, High Veg.: Tair) \\
Vegetation dielectric model & Mätzler \\
Vegetation dielectric model (cold) & Not frozen \\
\hline Snow emission model & HUT multi layer model $\left(N_{\max }=1\right)$ \\
Snow volumetric moisture model & Anderson \\
\hline Atmospheric emission model & Input (RTTOV) \\
\hline
\end{tabular}

\section{Results And Discussion}

\subsection{Offline Experiments}

\subsubsection{Global Distributions}

Figure 1a,b show global map of 2017-2018 boreal winter mean brightness temperature observed from GCOM-W AMSR2 at $10.65 \mathrm{GHz}, \mathrm{V}$ polarization (10V) and $10.65 \mathrm{GHz}, \mathrm{H}$ polarization $(10 \mathrm{H})$. 
The number of observations used in the statistics at $10 \mathrm{~V}$ is provided in Figure 1c. Figure $1 \mathrm{~d}$ shows the fraction of high vegetation in H-TESSEL as well as location of points [A] and [B] used for the times series case studies discussed in Sections 3.1.2 and 3.1.3. They illustrate results of CMEM in areas without or with high vegetation. Results from Figure $1 \mathrm{a}-\mathrm{c}$ are computed in each $2.0^{\circ}$ lat $\times$ $2.0^{\circ}$ lon bin. Large parts of observations are distributed in the northern region including boreal forests. Because of the difference such as reflectivity on the snow-covered soil surface [61], the average brightness temperature at $10 \mathrm{H}$ is about $15 \mathrm{~K}$ less than $10 \mathrm{~V}$. Especially, the relatively low brightness temperature areas at $10 \mathrm{H}$ correspond to areas without high vegetation (e.g., north Siberia, Canadian Arctic Archipelago).
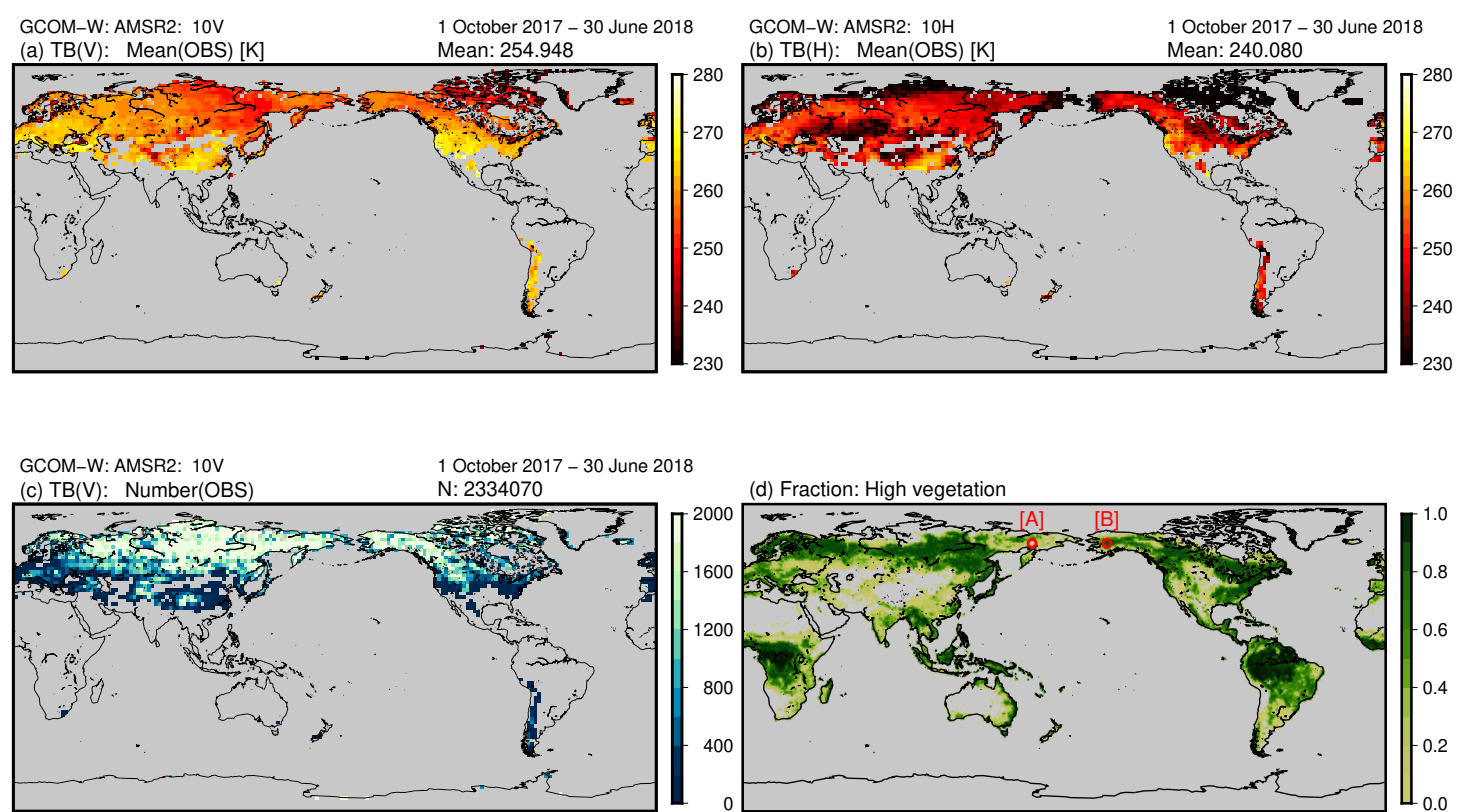

Figure 1. Maps of mean observed AMSR2 $10.65 \mathrm{GHz}$ brightness temperature at $\mathrm{V}(\mathbf{a})$ and $\mathrm{H}(\mathbf{b})$ polarizations, number of $10.65 \mathrm{GHz}(\mathrm{V})(\mathrm{c})$ observations used in the statistics, computed in each $2.0^{\circ}$ lat $\times 2.0^{\circ}$ lon bin and over the time period 1 October 2017 to 30 June 2018 for snow-covered area (excluding glaciers and ice shelves). Map (d) shows fraction of high vegetation in CMEM simulations (Section 2.5). [A] $\left(\right.$ lon $=162.0^{\circ} \mathrm{E}$, lat $\left.=64.0^{\circ} \mathrm{N}\right)$ and $[\mathrm{B}]\left(\mathrm{lon}=156.0^{\circ} \mathrm{W}\right.$, lat $\left.=64.0^{\circ} \mathrm{N}\right)$ in $(\mathrm{d})$ are sample point without and with high vegetation, respectively.

Figure 2 presents the maps of mean simulated brightness temperature, mean first guess departure $(\mathrm{O}-\mathrm{B})$, computed as the differences between observation and simulation (bias), standard deviation of O-B (STDV) and Pearson product-moment correlation coefficient (R) from experiment ML5 (Table 3) at $10 \mathrm{~V}$ and $10 \mathrm{H}$ for the same period as Figure 1. Global mean statistics are also indicated on the top of each panel in Figure 2. They indicate an overall better agreement with AMSR2 is obtained at 10V compared to $10 \mathrm{H}$, in terms of bias, STDV and correlation. Figure 2c,d show generally positive mean first guess departure values for areas with high vegetation (e.g., Central Siberia), and negative O-B for areas without high vegetation (extreme north Siberia). Although this pattern is present both at $10 \mathrm{~V}$ and $10 \mathrm{H}$, it is more pronounced at $10 \mathrm{H}$. Maps of correlation, Figure $2 \mathrm{~g}$, h, show a very good agreement between CMEM ML5 and AMSR2, especially at 10V, with values larger than 0.8 in Siberia, Alaska and western Russia. These areas correspond well to areas with large fraction of high vegetation (Figure 1d). STDV is also relatively low in these areas. 

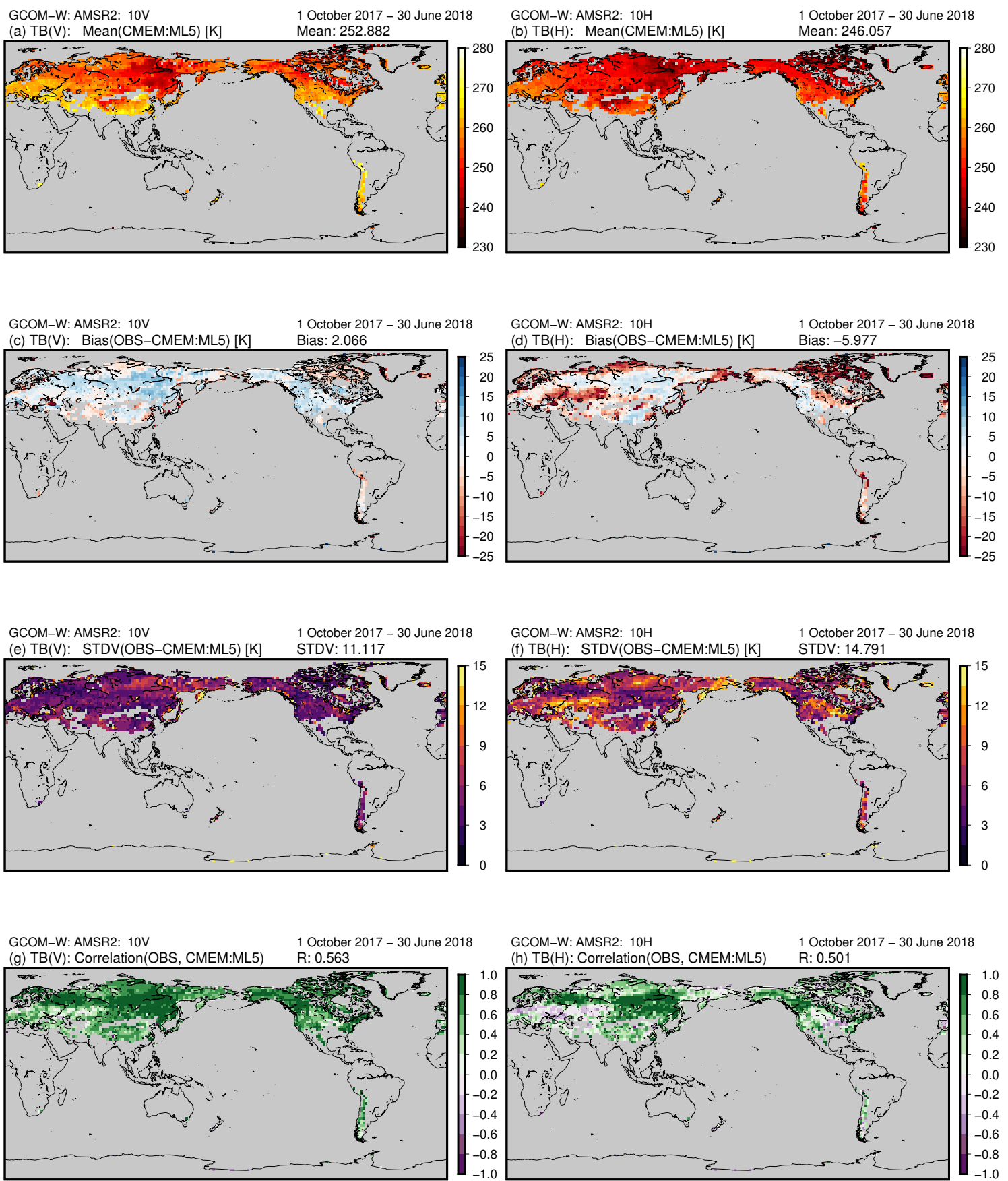

Figure 2. Maps of brightness temperature at $10.65 \mathrm{GHz}$ mean from the CMEM ML5 experiment $(\mathbf{a}, \mathbf{b})$, mean first guess departure $(\mathrm{O}-\mathrm{B})$ computed as AMSR2 observations minus CMEM ML5 (c,d), first guess departure standard deviation $(\mathbf{e}, \mathbf{f})$ and correlation $(\mathbf{g}, \mathbf{h})$ between observations and CMEM ML5. Left $(\mathbf{a}, \mathbf{c}, \mathbf{e}, \mathbf{g})$ and right $(\mathbf{b}, \mathbf{d}, \mathbf{f}, \mathbf{h})$ show $\mathrm{V}$ and $\mathrm{H}$ polarizations, respectively. Statistics are computed in each $2.0^{\circ}$ lat $\times 2.0^{\circ}$ lon bin and over the time period 1 October 2017 to 30 June 2018 .

\subsubsection{Impact of Multi-Layer Snow}

Figure 3 shows observed and simulated brightness temperatures at $10.65 \mathrm{GHz}$ at location [A] (see Figure 1d). It is representative of areas without high vegetation, which is suitable to assess the impact of multi-layer snow modelling without complex snow vegetation interactions. The figure includes results from offline experiments SL1, ML1 and ML5 (see Table 3), and shows the soil and snow temperature input to CMEM. Also shown in Figure 3 are time-height plots of snow density 
and temperature with periods of the presence of wet snow depicted as the shaded areas. In each experiment, in periods of dry snow, simulated brightness temperature shows less short term variability than the AMSR2 observations. However the figure indicates a good agreement between the ML1 snow temperature variability and AMSR2 brightness temperature during dry snow periods. In contrast, CMEM brightness temperature variability corresponds more closely with soil temperature. This is due to the near transparency of the snowpack at $10.65 \mathrm{GHz}$; i.e., the sensor is responding to radiance from the soil rather than the overlying snow.

In all the CMEM experiments, simulated brightness temperatures gradually decrease through the winter season while snow density increases. The importance of structure of the snowpack on the simulated brightness temperature is seen when comparing the results of the ML1 run versus the ML5 run; the difference between the CMEM input for these runs is the layer structure of snow (temperature, density and moisture) only (total snow depth and the soil and atmosphere parameters are the same). For instance, with increasing density in the lower layer of snow, simulated brightness temperature of ML5 is lower than ML1 after February at 10V. One of the reasons is that the increase in grain size from Equation (2) causes greater attenuation of radiance from soil.

In wet snow periods, mainly during the melting season, both observed and simulated brightness temperature are characterized by increased short term variability. Simulated brightness temperature in wet snow conditions is about $20 \mathrm{~K}$ higher than that of the dry conditions. As the snow liquid water content increases, the snowpack becomes less transparent, with increasing snow temperature and decreasing soil temperature contributions to the overall land surface emission. Because the snow temperature is close to the melting point of water in single-layer snow and the diurnal variation is small (SL1 and ML1), the diurnal variation of the simulated brightness temperature is small. On the other hand, there is diurnal variation of simulated brightness temperature in multi-layer snow (ML5), reflecting the effect of diurnal snow temperature variation near the snow-atmosphere interface.

Figure 4 shows time series of the statistics (5-day moving averages) of simulated brightness temperatures compared to GCOM-W AMSR2 observations at $10.65 \mathrm{GHz}$ in the 2017-2018 boreal winter. The target area is snow-covered without high vegetation (fraction of high vegetation is 0 ), and excludes glaciers and ice shelves, in the Northern Hemisphere. These results confirm findings from the point scale analysis at location [A] above. All experiments show better performances of CMEM simulations during dry snow periods and degraded bias, STDV and correlation during the melting season. Using H-TESSEL data with a multi-layer snow scheme (ML1 and ML5) leads to reduced STDV, higher correlation values and a small difference between ML1 and ML5.

Figure 5 shows statistics of CMEM compared with AMSR2 observations at 06V/H, 10V/H, $19 \mathrm{~V} / \mathrm{H}$, for the same period and area as in Figure 4. Due to the large sample size (about 900,000), the $95 \%$ confidence interval for each statistic is less than $0.1 \mathrm{~K}$ in bias and STDV and 0.01 in correlation (not shown). At all frequencies, better agreement with the AMSR2 observations is obtained at vertical than at horizontal polarization. As shown in Figure 4, STDV and correlation for ML1 and ML5 are slightly better than SL1 and the difference increases with higher frequency where the effect of snow becomes larger. Arduini et al. [14] showed that for thick and cold snowpacks the enhanced vertical resolution enables a better simulation of the internal snow density variability in H-TESSEL offline experiments. Although the difference between ML1 and ML5 is small, these improvements explain better results in ML5 and ML1 than in SL1. 

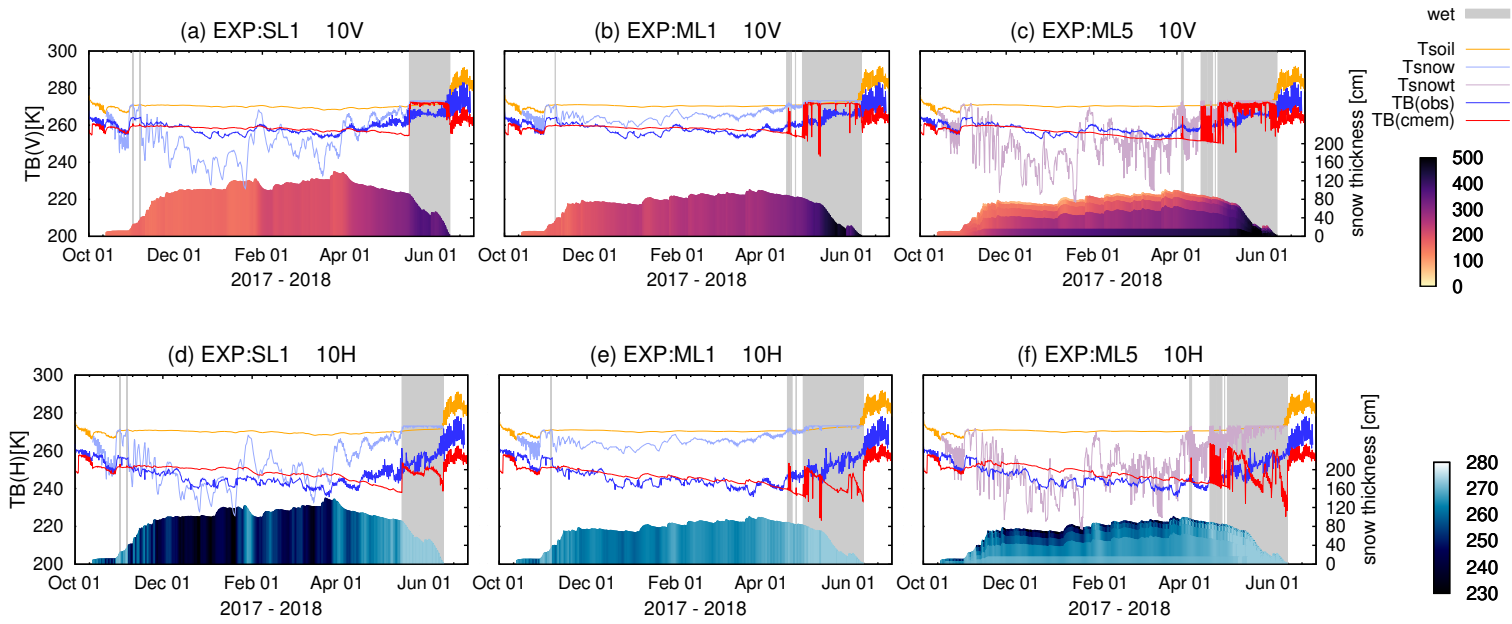

Figure 3. Time series, at grid point $[\mathrm{A}]\left(\mathrm{lon}=162.0^{\circ} \mathrm{E}\right.$, lat $=64.0^{\circ} \mathrm{N}$, see Figure $1 \mathrm{~d}$ ), of $10.65 \mathrm{GHz}$ brightness temperature from AMSR2 (blue) and CMEM (red), H-TESSEL top soil layer temperature (orange), snow temperature (light blue in SL1 and ML1) and temperature of top snow layer in ML5 (light purple), from 1 October 2017 to 30 June 2018, for V (top) and H (bottom), for SL1 (left), ML1 (middle) and ML5 (right). Coloured areas show time-height plot of snow density [kg m$\left.{ }^{-3}\right]$ (top) and temperature $[\mathrm{K}]$ (bottom). Wet snow periods are shaded in grey.
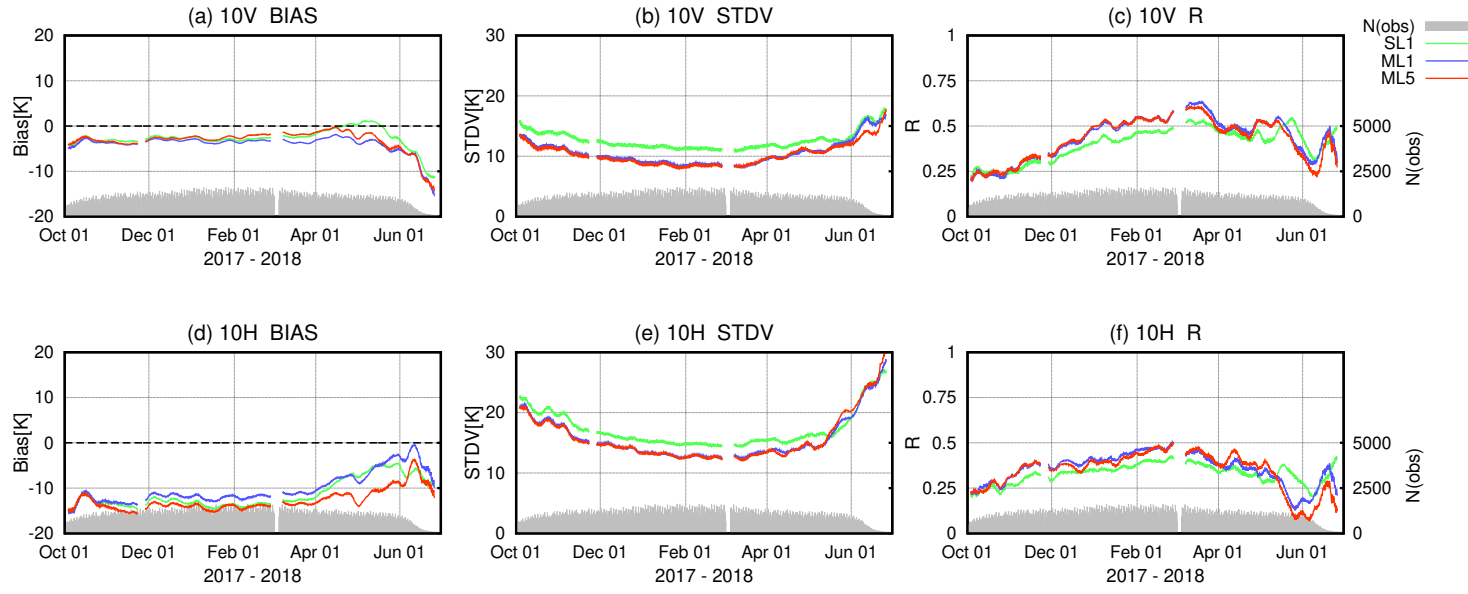

Figure 4. Time series (5-day moving averages) of statistics (left: bias, center: STDV, right: correlation) of simulated brightness temperature compared to GCOM-W AMSR2 observations at $10.65 \mathrm{GHz}(\mathrm{V})$ (top) and $10.65 \mathrm{GHz}(\mathrm{H})$ (bottom) from 1 October 2017 to 30 June 2018. Target area is snow-covered area without high vegetation, and excluding glacier and ice shelves, in the Northern Hemisphere. Bar chart shows number of data for ML5 simulations (Table 3).

(a) Bias

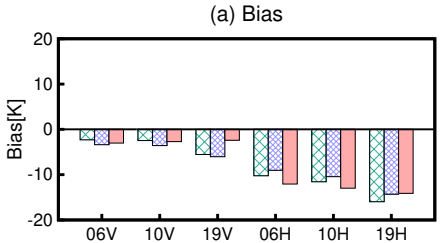

(b) STDV

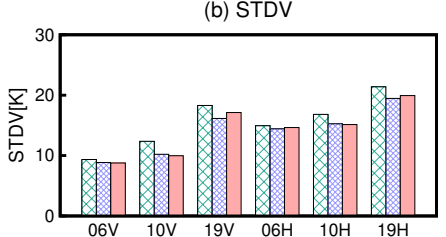

(c) $\mathrm{R}$

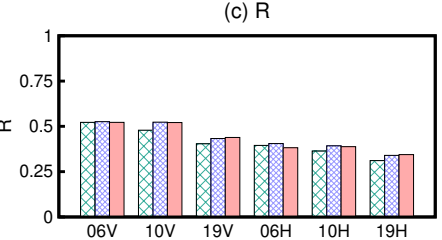

Figure 5. Statistics of simulated brightness temperature compared to GCOM-W AMSR2 observations for the time period 1 October 2017 to 30 June 2018. Target area is snow-covered area without high vegetation, and excluding glacier and ice shelves, in the Northern Hemisphere. 


\subsubsection{Impact of High Vegetation Over Snow}

Figure 6 shows observed and simulated brightness temperatures from ML5, TSO, ICE, KOU and $\mathrm{NOH}$ (see experiments list in Table 3), at $10.65 \mathrm{GHz} H$ polarization, at point scale location [B] (see Figure 1d). It also shows time-height plots of snow temperature from offline experiments ML5. At this location, the fraction of high vegetation is $90 \%$ in H-TESSEL, therefore the optical depth and the emission of vegetation largely influence the simulated TOA brightness temperature. Figure $6 \mathrm{a}$ shows good agreement between observed and ML5 brightness temperature, while the short-term variability of TSO (setting as CMEM v5.1 default) is underestimated during the snow season. Although there is about $15 \mathrm{~K}$ difference, the temporal variability of the air temperature agrees well with that of the observed brightness temperature. It illustrates that using air, rather than soil, temperature as an approximation for high vegetation canopy temperature is suitable. In contrast to results presented for areas without high vegetation (Figure 3), all CMEM configurations show a low sensitivity to wet snow content over high vegetation. It is explained by the attenuation effect of the vegetation layer.

When air temperature at $2 \mathrm{~m}$ is used as an approximation for high vegetation temperature, it can reach temperature far below freezing point. In this paper, the Wegmüller model is used to model the vegetation optical depth because it is applicable to a larger range of frequencies $(1-100 \mathrm{GHz})$ and accounts for the dielectric constant of vegetation (Table 2). While a non-frozen water dielectric model is used for ML5 and TSO in Figure 6a, dielectric models that consider frozen water in high vegetation are applied for KOU and ICE in Figure 6b. In ICE, the dielectric constant of ice is used when the vegetation canopy temperature drops below $-0.5^{\circ} \mathrm{C}$. In these conditions, the simulated brightness temperature is the same as the case without high vegetation $(\mathrm{NOH})$, and the difference from the observed brightness temperature becomes large. It is clearly shown in Figure $6 \mathrm{~b}$ for January-February with very cold air temperatures, observed brightness temperatures below $240 \mathrm{~K}$ and simulated values for ICE staying around $250 \mathrm{~K}$. In KOU, the vegetation dielectric model takes into account the freezing point depression of vegetation related to the cold resistance. Therefore it shows good agreement with observation as ML5, except in cases when the vegetation temperature (air temperature) falls below $260 \mathrm{~K}$ at which point the dielectric constant of the vegetation layer is the same as that of ice. In these conditions, Figure 7 shows that the vegetation optical depth is close to 0 (Equations (1), (5) and (6)), the vegetation is transparent and top-of-vegetation brightness temperature is unrealistically driven by soil conditions. In other words, the simulated brightness temperatures of ICE and KOU in severe cold winter conditions are close to the value of $\mathrm{NOH}$ (Figure 6b). These results suggest that it is not appropriate for the vegetation optical depth model of Wegmüller to use dielectric constant models largely influenced by ice.

Figure 8 shows statistics between CMEM and AMSR2 observations, for snow-covered (excluding glaciers and ice shelves) areas with high vegetation in the Northern hemisphere. Comparison between TSO and ML5, shows larger bias (O-B) values for ML5. This is explained by the fact that ML5 uses air temperature at $2 \mathrm{~m}$ for high vegetation, so at all frequencies it is colder than TSO, which uses soil temperature. Although ML5 displays higher short term variability than TSO leading to larger STDV at $6.925 \mathrm{GHz}$, the STDV scores are neutral at $10.65 \mathrm{GHz}$ and better than TSO at $18.7 \mathrm{GHz}$. The most important improvement of ML5 compared to the other CMEM configurations is in terms of correlation values which are improved at all frequencies by more than 0.15 at $\mathrm{V}$ polarization and to a less extent at $\mathrm{H}$ polarization. These results show that accounting for vegetation canopy temperature is crucial to simulate the contribution of vegetation to the brightness temperature over snow covered areas. 

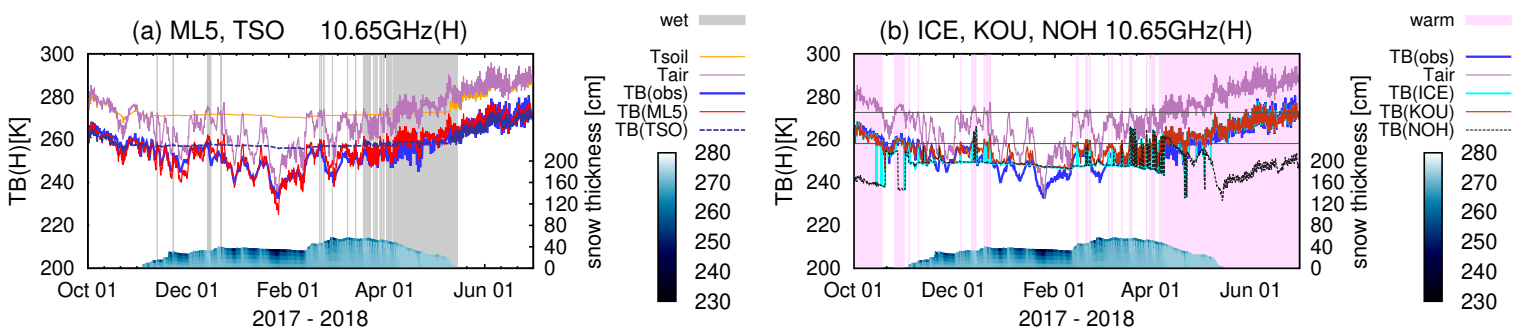

Figure 6. Time series, at grid point $[\mathrm{B}]\left(\mathrm{lon}=156.0^{\circ} \mathrm{W}\right.$, lat $=64.0^{\circ} \mathrm{N}$, see Figure $\left.1 \mathrm{~d}\right)$, of $10 \mathrm{H}$ brightness temperature from AMSR2 (blue), CMEM (in a: ML5 in red and TSO in dotted blue, and in $\mathbf{b}$ : ICE in cyan, $\mathrm{KOU}$ in red and $\mathrm{NOH}$ in dotted blue), H-TESSEL top soil layer temperature (orange in a), air temperature at $2 \mathrm{~m}$ (light purple), from 1 October 2017 to 30 June 2018. Blue coloured areas show time-height plot of ML5 snow temperature in K. Wet snow periods are shaded in grey in (a), and warm periods (Tair $\geq-0.5^{\circ} \mathrm{C}$ ) are shaded in light pink in (b). Horizontal Black lines in (b) show $\mathrm{T} x=-0.5^{\circ} \mathrm{C}$.

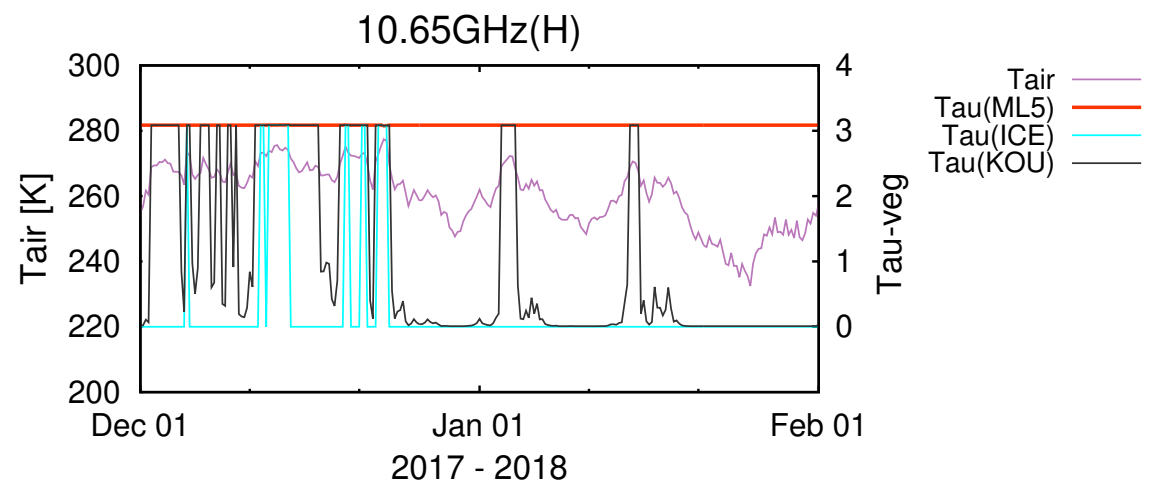

Figure 7. Time series of air temperature at $2 \mathrm{~m}$ in $\mathrm{K}$ (light purple line) and optical depth of vegetation (Tau) from ML5 (red), ICE (light blue) and KOU (black), at grid point [B] (lon $=156.0^{\circ} \mathrm{W}$, lat $=64.0^{\circ} \mathrm{N}$, fraction of high vegetation $=90 \%$ ) from 1 December 2017 to 1 February 2018 at $10.65 \mathrm{GHz}(\mathrm{H})$.
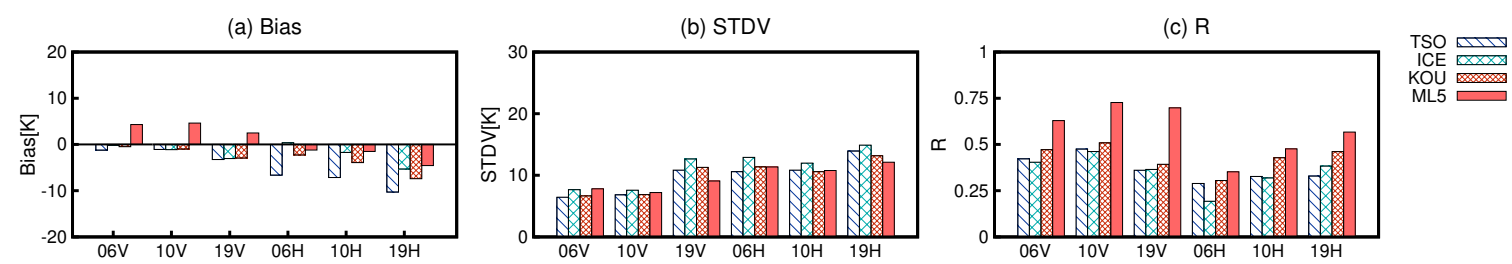

Figure 8. Statistics of simulated brightness temperature compared to GCOM-W AMSR2 observations for the time period 1 October 2017 to 30 June 2018. Target area is snow-covered (excluding glacier and ice shelves) area with high vegetation in the Northern hemisphere.

\subsubsection{Coupled Experiments with Cmem-Rttov in the Ifs}

Figure 9 shows global maps of mean brightness temperature (in K) for January 2019 as observed by AMSR2 (top), from IFS:ATLAS (middle) and IFS:CMEM (bottom). Although the periods analyzed are different and shorter, the geographical distribution and patterns are similar to those discussed in the previous sub-section for the offline experiments (Figure 1a,b). Figure $9 c$ and d show that the IFS:ATLAS experiment underestimates brightness temperature values compared to AMSR2 observations, with mean values of $253.3 \mathrm{~K}$ and $240.7 \mathrm{~K}$ for AMSR2 V and $\mathrm{H}$ observations versus $247.6 \mathrm{~K}$ and $234.0 \mathrm{~K}$ for IFS:ATLAS. The negative bias is especially pronounced at $\mathrm{H}$ polarization in extreme north Siberia and Alaska where the fraction of high vegetation is low. In contrast, IFS:CMEM mean brightness temperature values are $249.7 \mathrm{~K}$ and $244.5 \mathrm{~K}$ at $\mathrm{V}$ and $\mathrm{H}$ polarizations, in relative better agreement with AMSR2 observations, but with a positive bias at $\mathrm{H}$ polarization. 

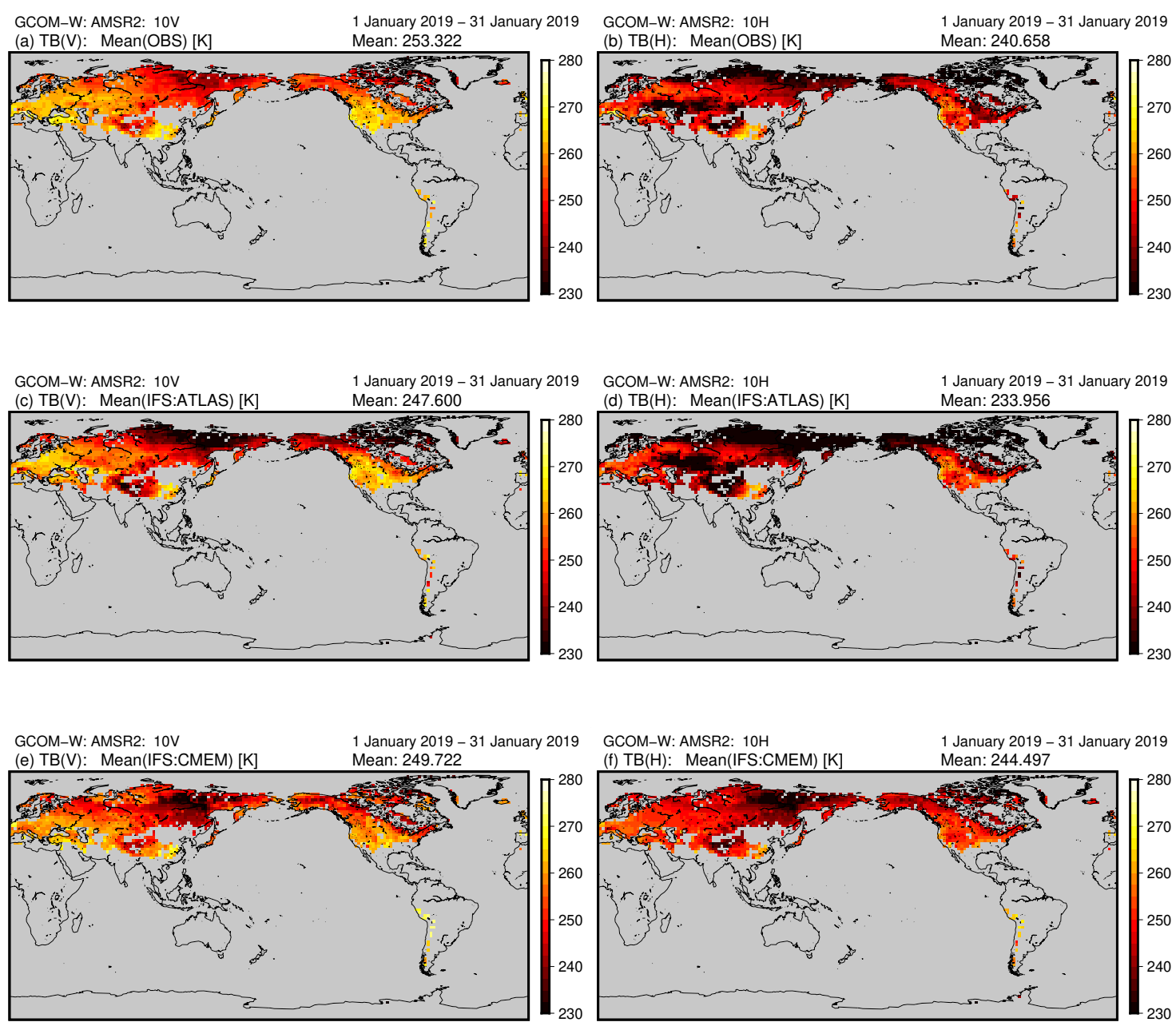

Figure 9. Mean brightness temperatures in $\mathrm{K}$ at $10.65 \mathrm{GHz}$ over snow-covered areas (excluding glacier and ice shelves), from AMSR2 (a,b), IFS:ALTAS (c,d) and IFS:CMEM (e,f), at V (left: $\mathbf{a}, \mathbf{c}, \mathbf{e})$ and H (right: $\mathbf{b}, \mathbf{d}, \mathbf{f}$ ) polarizations. Means are computed in each $2.0^{\circ}$ lat $\times 2.0^{\circ}$ lon bin and over the time period 1 to 31 January 2019.

Figures 10 and 11 show maps of statistic from experiment IFS:ATLAS and IFS:CMEM at $10.65 \mathrm{GHz}$ for January 2019. Note that due to the influence of quality control in the IFS for atmospheric optical depth and radiance used by CMEM, the number of comparisons for IFS:ATLAS and IFS:CMEM differ slightly. Regarding IFS:CMEM, the geographical distribution of bias and correlation are similar to the offline experiment results that were obtained for a full winter season (Figure 2). However first guess departure standard deviation is smaller in IFS:CMEM for January 2019 than in the offline ML5 experiment. In January, the area in which the snow is melting is very limited in the Northern Hemisphere, therefore the IFS:CMEM experiment is not affected by wet snow conditions, in contrast to ML5 seasonal results that included the season in which snow melts up to April. Additionally, the specification that the offline land-surface experiments do not have snow assimilation might contribute to the differences. The IFS:ATLAS and IFS:CMEM experiments have positive mean first guess departure values of $5.8 \mathrm{~K}$ and $3.6 \mathrm{~K}$ at $\mathrm{V}$ polarization, indicating model underestimation of brightness temperature values. At $\mathrm{H}$ polarization mean first guess departures are $6.7 \mathrm{~K}$ and $-3.8 \mathrm{~K}$, with model underestimation in IFS:ATLAS and overestimation in IFS:CMEM. Differences between IFS:ATLAS and IFS:CMEM mean first guess departures are largest in north Siberia, Alaska and over the Tibetan Plateau, which are regions characterized by low fraction of high vegetation. Since the snowpack is dry in this period, radiance from the soil is dominant in these regions. In IFS:CMEM, the Wegmüller model is used for soil roughness model because it is applicable to a larger range of 
frequencies (1-100 GHz) (Table 5). Wegmüller et al. [44] pointed out that the model mainly fails in predicting the high reflectivity values observed for soils that are smoothed by repeated precipitation, as typically occurs on bare fields during wintertime. Because a priority on a wide applicability is set and not on the optimization of the model for a specific case, the roughness parameter is globally uniform. This result suggests a necessity of considering the characteristics of regions in soil roughness model such as the Wigneron model. First guess departure standard deviation values are $7.7 \mathrm{~K}(\mathrm{~V})$ and 9.5 K (H) for IFS:ATLAS, and $6.9 \mathrm{~K}(\mathrm{~V})$ and $10.9 \mathrm{~K}(\mathrm{H})$ for IFS:CMEM. The correlation coefficient of IFS:ATLAS tends to be better than that of IFS:CMEM. In terms of correlation, IFS:ATLAS shows better performance with $0.85(\mathrm{~V})$ and $0.80(\mathrm{H})$, than IFS:CMEM with $0.70(\mathrm{~V})$ and $0.43(\mathrm{H})$. These results show that the temporal dynamics is better captured by IFS:ATLAS than IFS:CMEM whereas mean values are better represented by IFS:CMEM.

Figure 12 shows observed and simulated brightness temperatures at $10.65 \mathrm{GHz}(\mathrm{V})$ and $89.0 \mathrm{GHz}$ (V) at location [A] (see Figure 1d) for January 2019. The figure also shows soil and skin temperatures used for IFS:CMEM and IFS:ATLAS. At this location, the fraction of high vegetation is 0 and the snowpack is dry in this period. Therefore, IFS:CMEM brightness temperature is significantly affected by soil temperature. On the other hand, since emissivity is constant in this period but variation of skin temperature is large, the temporal dynamics of the brightness temperature is larger for IFS:ATLAS than for IFS:CMEM. This tendency is seen at both $10 \mathrm{~V}$ and $89 \mathrm{~V}$. This figure illustrates that best agreement with AMSR2 observations is obtained with IFS:CMEM at 10V, whereas IFS:ATLAS performs better at $89 \mathrm{~V}$. This result suggests that CMEM needs to consider the information of snow near the surface layer more properly at high frequencies.

Figure 13 provides the kernel density estimation of the brightness temperature differences between the observations and simulations, at all frequencies and polarizations for January 2019 over snow-covered areas without high vegetation (left) and with high vegetation (right). Since the statistical characteristics of each channel are reflected for the emissivity, the differences in the distributions between $\mathrm{V}$ polarization and H polarization of IFS:ATLAS is smaller than that of IFS:CMEM. The top three left panels show narrow distributions of first guess departures in the absence of high vegetation, at V polarization for IFS:CMEM at frequencies lower than $20 \mathrm{GHz}$. These distributions are associated with smaller standard deviation values than in the other configurations. It suggests that CMEM improves the emission modelling compared to the emissivity atlas in these conditions. However, at frequencies larger than $20 \mathrm{GHz}$, the mean first guess departure and standard deviation values are larger for IFS:CMEM than IFS:ATLAS (lower three panels of Figure 13). This is consistent with Figure 12 and the previous study from [7] which showed similar issues with the CRTM over snow and ice regions. Adding to the snow emission modeling uncertainties, it could be partly due to the difficulty in providing inputs that reflect complex snow conditions. For instance, around $89 \mathrm{GHz}$, although the effect of snow grain size for snow emissivity becomes large [1], grain size in CMEM is given by simple parameterization from Equation (2). Observations also show cases in which the grain size is not well correlated with the density of the snowpack [62]. These results suggest that further studies are needed in order to improve emissivity values simulated by CMEM at high frequency. 

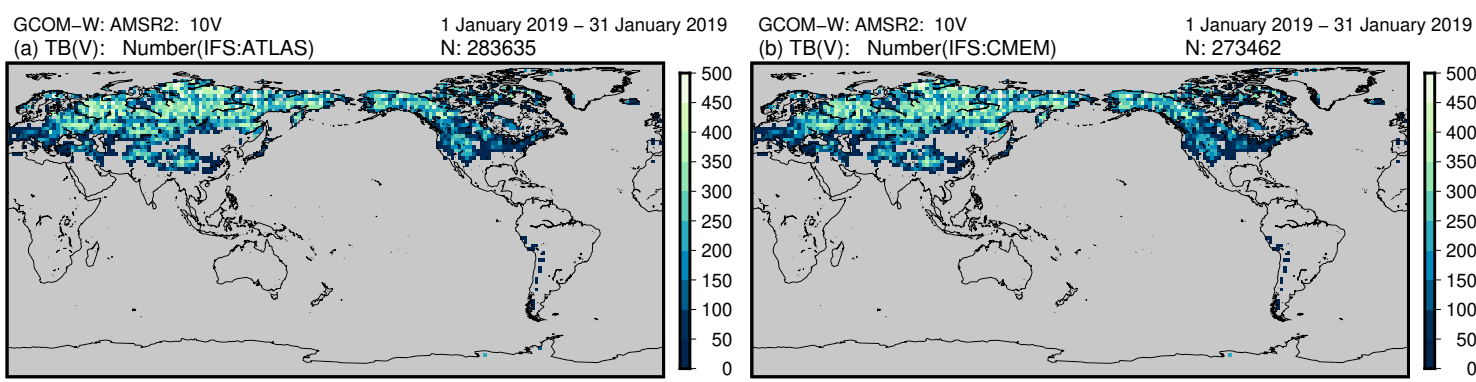

GCOM-W: AMSR2: $10 \mathrm{~V}$

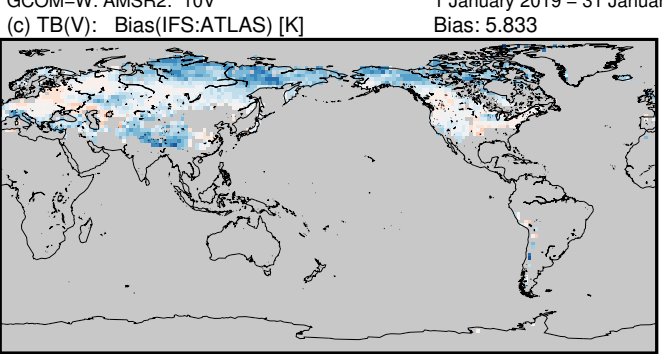

GCOM-W: AMSR2: 10V \begin{tabular}{ll} 
(d) TB(V): Bias(IFS:CMEM) $[K]$ & Banuary 20 \\
\hline
\end{tabular}

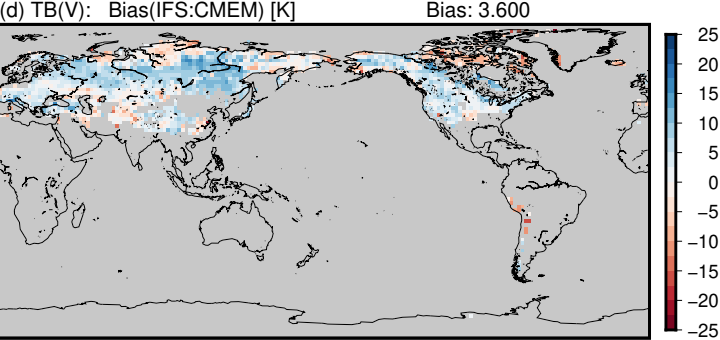

GCOM-W: AMSR2: 10V

January 2019 - 31 January 2019

GCOM-W: AMSR2: 10V

(f) TB(V): STDV(IFS

1 January 2019 - 31 January 2019
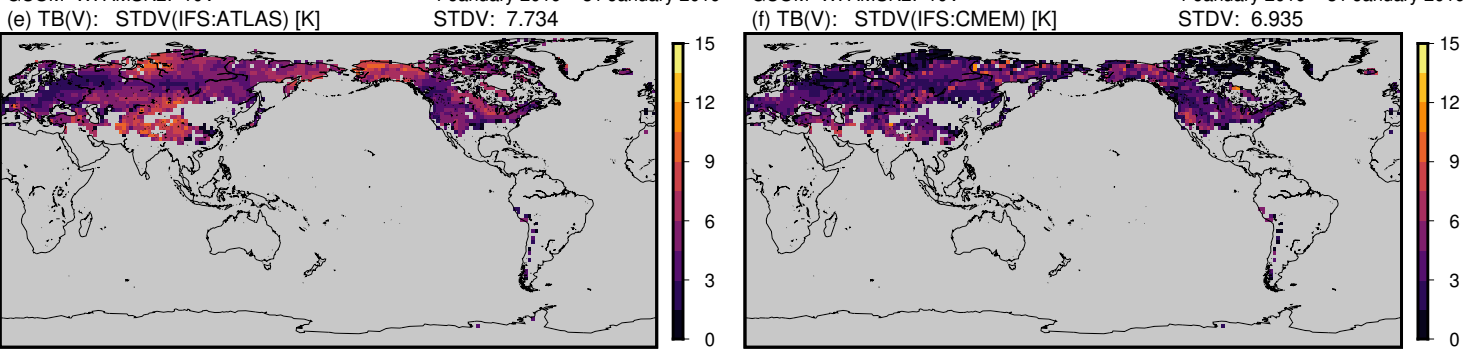

GCOM-W: AMSR2: $10 \mathrm{~V}$

January $2019-31$ January 2019
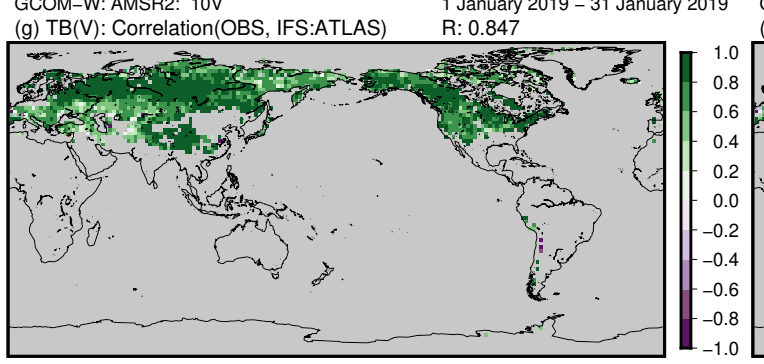

GCOM-W: AMSR2: 10V 1 January 2019 - 31 January 2019 (h) TB(V): Correlation(OBS, IFS:CMEM) $\quad$ R: 0.699

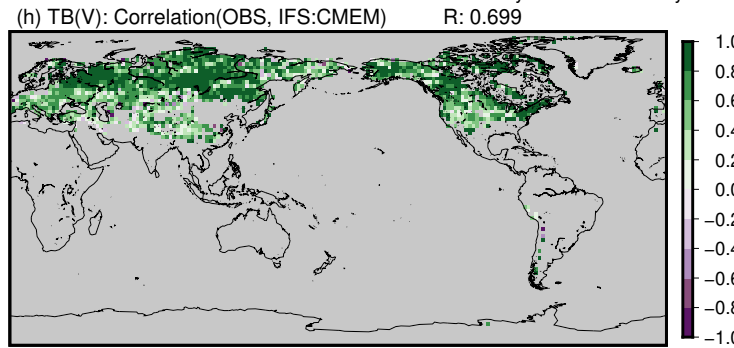

Figure 10. Statistics against AMSR2 observations at $10.65 \mathrm{GHz} \mathrm{V}$ polarization for the IFS-ATLAS (left: $\mathbf{a}, \mathbf{c}, \mathbf{e}, \mathbf{g}$ ) and IFS:CMEM (right: $\mathbf{b}, \mathbf{d}, \mathbf{f}, \mathbf{h}$ ) experiments for January 2019, including number of observations $\mathrm{N}(\mathbf{a}, \mathbf{b})$, first guess departure $\mathrm{O}-\mathrm{B}$ in $\mathrm{K}(\mathbf{c}, \mathbf{d})$, first guess departure standard deviation STDV in $\mathrm{K}(\mathbf{e}, \mathbf{f})$ and correlation $(\mathbf{g}, \mathbf{h})$. Statistics are computed in each $2.0^{\circ}$ lat $\times 2.0^{\circ}$ lon bin and over the period 1 to 31 January 2019. 

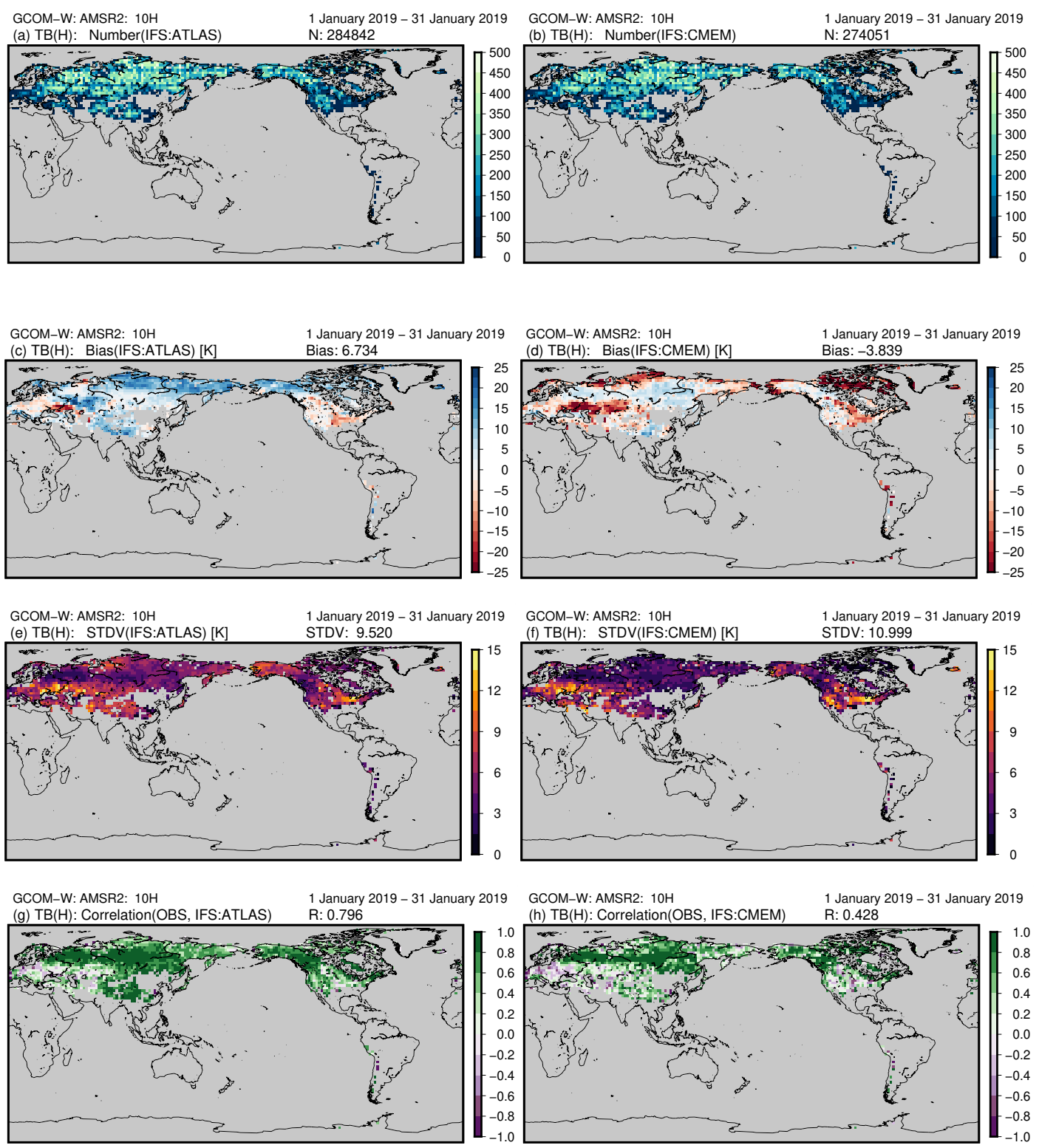

Figure 11. As in Figure 10 but at $\mathrm{H}$ polarization.

(a) $10.65 \mathrm{GHz}(\mathrm{V})$
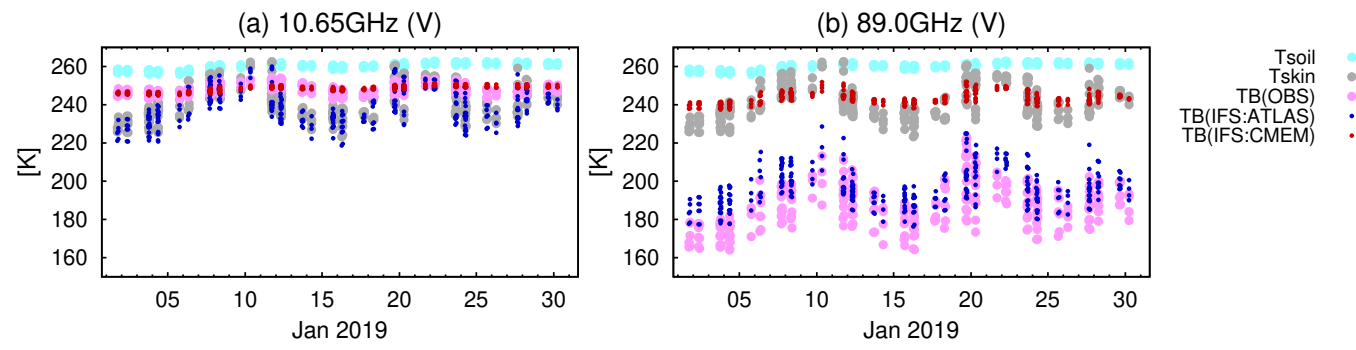

Figure 12. Time series of brightness temperature from AMSR2 (gray), IFS:ATLAS(blue), IFS:CMEM(red), top soil layer temperature (cyan), skin temperature (pink) for January 2019. Left 10.65 $\mathrm{GHz}(\mathrm{V})$ and right $89.0 \mathrm{GHz}(\mathrm{V})$. Figures show data contained in a $2.0^{\circ}$ lat $\times 2.0^{\circ}$ lon bin centered at point $[\mathrm{A}]\left(\right.$ lon $=162.0^{\circ} \mathrm{E}$, lat $=64.0^{\circ} \mathrm{N}$, see Figure $\left.1 \mathrm{~d}\right)$. 

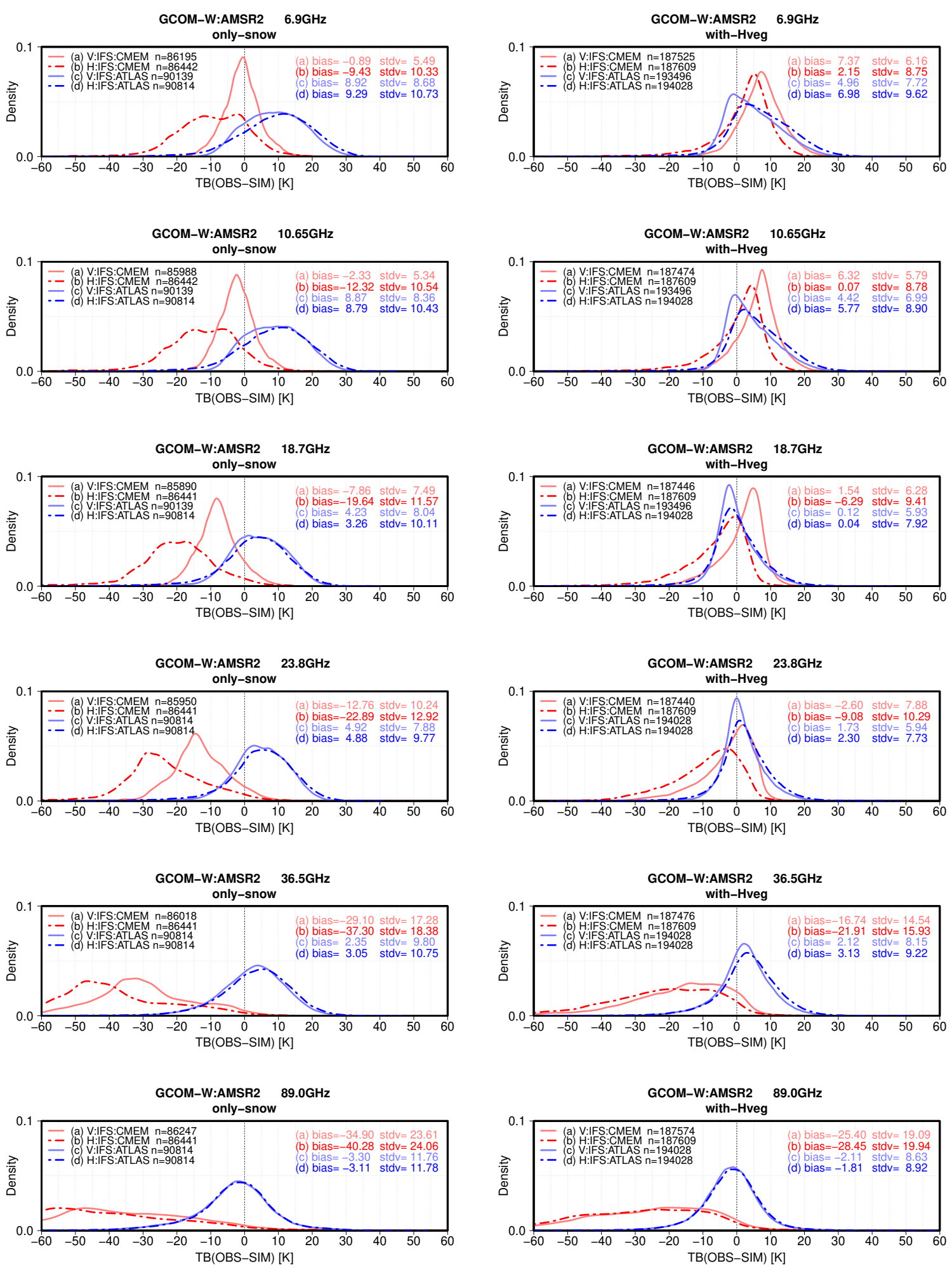

Figure 13. Kernel density estimation of AMSR2 first guess departure (O-B) in K, for January 2019, for IFS:ATLAS (blue) and IFS:CMEM (red), at V (solid lines) and $\mathrm{H}$ (dotted lines), for snow-covered (excluding glacier and ice shelves) area without (left) and with (right) high vegetation, for the six AMSR2 frequencies from $6.9 \mathrm{GHz}$ (top) to $89 \mathrm{GHz}$ (bottom). 


\section{Conclusions}

This study investigated the usage of CMEM to estimate land surface emissivity over snow-covered areas. The HUT multi-layer snow emission model and new parameterizations, which allow for expansion of the target frequency, were implemented in CMEM. The performance of the new model and parameterizations in CMEM over snow-covered areas was evaluated by offline experiments, the results from CMEM were compared with AMSR2 measurements. From the CMEM offline experiments for a 9-month period covering the boreal winter from 2017 to 2018, using H-TESSEL results with multi-layer snow scheme as input and multi-layer HUT snow emission model led to reduced first guess departure standard deviation values and higher correlation values. The improvement was mainly brought by better simulation of snow in the multi-layer land surface model H-TESSEL rather than by the multi-layer HUT model. In areas with high vegetation cover over snow, using air temperature at $2 \mathrm{~m}$ as a proxy for high vegetation canopy temperature led to improvement of the correlation with observations. Especially, at $10.65 \mathrm{GHz} \mathrm{V}$ polarization, the correlation values were larger than 0.8 in Siberia, Alaska and western Russia. Although CMEM showed low sensitivity to snow properties over high vegetation, due to the attenuation effect of the vegetation layer, the vegetation optical depth and vegetation emission largely influenced TOA brightness temperatures over these areas. When the Wegmüller model was used to model the vegetation optical depth, which is applicable to a larger range of frequencies, it was not appropriate to use vegetation dielectric constant models largely influenced by ice because the vegetation optical depth became too low in frozen conditions. From the CMEM-RTTOV coupled experiments in the IFS system, conducted for January 2019, the emissivity calculated from CMEM was shown to improve simulated brightness temperature at low frequency over snow, compared to using the emissivity atlas TELSEM ${ }^{2}$ as input of RTTOV. However, the improvement depends on the polarization and fraction of vegetation. The kernel density estimation of the brightness temperature differences between the observations and simulations showed a clear improvement at $\mathrm{V}$ polarization below $20 \mathrm{GHz}$ in the area without high vegetation, but no improvement for other conditions. Results showed increased errors, when using CMEM compared to the atlas, at frequencies higher than $20 \mathrm{GHz}$, especially in areas devoid of high vegetation. These results show the potential of multi-layer modeling radiative transfer approaches at low frequencies. However, they emphasize that further studies are needed in order to improve emissivity modeling to support developments of coupled land-atmosphere assimilation of surface-sensitive satellite data.

Author Contributions: Conceptualization, Y.H. and P.d.R.; methodology, Y.H. and P.d.R.; software, Y.H., P.d.R. and G.A.; writing—original draft preparation, Y.H.; writing—review and editing, P.d.R. and G.A.; visualization, Y.H.; supervision, P.d.R.; All the authors contributed to editing and revisions of the paper. All authors have read and agreed to the published version of the manuscript.

Funding: The work of Y. Hirahara was co-funded by ECMWF and JMA. The work of P. de Rosnay was funded by ECMWF. The work of G. Arduini was funded through the APPLICATE project. The APPLICATE has received funding from the European Union's Horizon 2020 research and innovation programme under grant agreement 727862 .

Acknowledgments: This study was carried out in collaboration between ECMWF and JMA. The authors would like to thank Alan Geer, Katrin Lonitz, Niels Bormann, Peter Weston and Stephen English for constructive discussion of this work.

Conflicts of Interest: The authors declare no conflict of interest. 


\section{Abbreviations}

The following abbreviations are used in this manuscript:

$\begin{array}{ll}\text { AMSR2 } & \text { Advanced Microwave Scanning Radiometer 2 } \\ \text { AMSU-A } & \text { Advanced Microwave Sounding Unit-A } \\ \text { ATMS } & \text { Advanced Technology Microwave Sounder } \\ \text { CMEM } & \text { Community Microwave Emission Modelling platform } \\ \text { CRTM } & \text { Community Radiative Transfer Model } \\ \text { ECMWF } & \text { European Centre for Medium-Range Weather Forecasts } \\ \text { GCOM-W } & \text { Global Change Observation Mission-Water } \\ \text { H-TESSEL } & \text { Hydrology-Tiled ECMWF Scheme for Surface Exchanges over Land } \\ \text { HUT } & \text { Helsinki University of Technology } \\ \text { IFS } & \text { Integrated Forecast System } \\ \text { JAXA } & \text { Japan Aerospace Exploration Agency } \\ \text { JMA } & \text { Japan Meteorological Agency } \\ \text { MHS } & \text { Microwave Humidity Sounder } \\ \text { NWP } & \text { Numerical Weather Prediction } \\ \text { RTTOV } & \text { Radiative Transfer for TOVS } \\ \text { SMOS } & \text { Soil Moisture and Ocean Salinity } \\ \text { SSM/I } & \text { Special Sensor Microwave Imager } \\ \text { SSMIS } & \text { Special Sensor Microwave Imager/Sounder } \\ \text { TB } & \text { brightness temperature } \\ \text { TELSEM } & \text { Tool to Estimate Land Surface Emissivities at Microwave Frequencies } \\ \text { TELSEM } & \text { Tool to Estimate Land Surface Emissivity from Microwave to Submillimeter Waves } \\ \text { TOA } & \text { Top of Atmosphere } \\ \text { TOVS } & \text { TIROS Operational Vertical Sounder } \\ \text { UN-FAO } & \text { United Nations-Food and Agriculture Organization } \\ \text { USGS-GLCC } & \text { United States Geophysical Survey-Global Land Cover Classification } \\ \end{array}$

\section{References}

1. Grody, N. Relationship between snow parameters and microwave satellite measurements: Theory compared with Advanced Microwave Sounding Unit observations from 23 to $150 \mathrm{GHz}$. J. Geophys. Res. Atmos. 2008, 113. [CrossRef]

2. Krzeminski, B.; Bormann, N.; Karbou, F.; Bauer, P. Improved use of surface sensitive microwave radiances over land at ECMWF. In Proceedings of the EUMETSAT Meteorological Satellite Conference, EUMETSAT, Darmstadt, Germany, 21-25 September 2009.

3. Geer, A.J.; Baordo, F.; Bormann, N.; English, S. All-Sky Assimilation of Microwave Humidity Sounders; ECMWF Technical Memorandum Number 741; ECMWF: Reading, UK, 2014.

4. Baordo, F.; Geer, A.J. Assimilation of SSMIS humidity-sounding channels in all-sky conditions over land using a dynamic emissivity retrieval. Q. J. R. Meteorol. Soc. 2016, 142, 2854-2866. [CrossRef]

5. Bormann, N.; Lupu, C.; Geer, A.; Lawrence, H.; Weston, P.; English, S. Assessment of the Forecast Impact of Surface-Sensitive Microwave Radiances Over Land and Sea-Ice; ECMWF Technical Memorandum Number 804; ECMWF: Reading, UK, 2017.

6. Karbou, F.; Gérard, E.; Rabier, F. Microwave land emissivity and skin temperature for AMSU-A and -B assimilation over land. Q. J. R. Meteorol. Soc. 2006, 132, 2333-2355. [CrossRef]

7. Prigent, C.; Liang, P.; Tian, Y.; Aires, F.; Moncet, J.L.; Boukabara, S.A. Evaluation of modeled microwave land surface emissivities with satellite-based estimates. J. Geophys. Res. Atmos. 2015, 120, 2706-2718. [CrossRef]

8. de Rosnay, P.; Muñoz-Sabater, J.; Albergel, C.; Isaksen, L.; English, S.; Drusch, M.; Wigneron, J.P. SMOS brightness temperature forward modelling and long term monitoring at ECMWF. Remote Sens. Environ. 2020, 237, 111424. [CrossRef]

9. Muñoz-Sabater, J.; Lawrence, H.; Albergel, C.; de Rosnay, P.; Isaksen, L.; Drusch, M.; Kerr, Y.; Mecklenburg, S. Assimilation of SMOS brightness temperature in the ECMWF Integrated Forecasting System. Q. J. R. Meteorol. Soc. 2019. [CrossRef] 
10. Pulliainen, J.; Hallikainen, M.; Grandell, J. HUT snow emission model and its applicability to snow water equivalent retrieval. IEEE Trans. Geosci. Remote Sens. 1999, 37, 1378-1390. [CrossRef]

11. Balsamo, G.; Albergel, C.; Beljaars, A.; Boussetta, S.; Cloke, H.; Dee, D.; Dutra, E.; Muñoz-Sabater, J.; Pappenberger, F.; de Rosnay, P.; et al. ERA-Interim/Land: A global land water resources dataset. Hydrol. Earth Syst. Sci. 2015, 19, 389-407. [CrossRef]

12. Balsamo, G.; Viterbo, P.; Beljaars, A.; van den Hurk, B.; Hirsch, M.; Betts, A.; Scipal, K. A revised hydrology for the ECMWF model: Verification from field site to terrestrial water storage and impact in the Itegrated Forecast System. J. Hydrometeorol. 2009, 10, 623-643. [CrossRef]

13. Dutra, E.; Balsamo, G.; Viterbo, P.; Miranda, P.; Beljaars, A.; Schär, C.; Elder, K. An improved snow scheme for the ecmwf land surface model: description and offline validation. J. Hydrometeorol. 2010, 11, 899-916. [CrossRef]

14. Arduini, G.; Balsamo, G.; Dutra, E.; Day, J.J.; Sandu, I.; Boussetta, S.; Haiden, T. Impact of a Multi-Layer Snow Scheme on Near-Surface Weather Forecasts. J. Adv. Model. Earth Syst. 2019, 11, 4687-4710. [CrossRef]

15. Saunders, R.; Matricardi, M.; Brunel, P. An improved fast radiative transfer model for assimilation of satellite radiance observations. Q. J. R. Meteorol. Soc. 1999, 125, 1407-1425. [CrossRef]

16. Saunders, R.; Hocking, J.; Turner, E.; Rayer, P.; Rundle, D.; Brunel, P.; Vidot, J.; Roquet, P.; Matricardi, M.; Geer, A.; et al. An update on the RTTOV fast radiative transfer model (currently at version 12). Geosci. Model Dev. 2018, 11, 2717-2737. [CrossRef]

17. Wang, D.; Prigent, C.; Kilic, L.; Fox, S.; Harlow, C.; Jimenez, C.; Aires, F.; Grassotti, C.; Karbou, F. Surface Emissivity at Microwaves to Millimeter Waves over Polar Regions: Parameterization and Evaluation with Aircraft Experiments. J. Atmos. Ocean. Technol. 2017, 34, 1039-1059. [CrossRef]

18. Imaoka, K.; Kachi, M.; Fujii, H.; Murakami, H.; Hori, M.; Ono, A.; Igarashi, T.; Nakagawa, K.; Oki, T.; Honda, Y.; et al. Global Change Observation Mission (GCOM) for Monitoring Carbon, Water Cycles, and Climate Change. Proc. IEEE 2010, 98, 717-734. [CrossRef]

19. JAXA. GCOM-W1 SHIZUKU Data Users Handbook, 1st ed.; Japan Aerospace Exploration Agency: Tokyo, Japan, 2013.

20. Geer, A.J.; Bauer, P.; Lopez, P. Direct 4D-Var assimilation of all-sky radiances. Part II: Assessment. Q. J. R. Meteorol. Soc. 2010, 136, 1886-1905. [CrossRef]

21. Kazumori, M.; Geer, A.J.; English, S.J. Effects of all-sky assimilation of GCOM-W/AMSR2 radiances in the ECMWF numerical weather prediction system. Q. J. R. Meteorol. Soc. 2016, 142, 721-737. [CrossRef]

22. Bauer, P.; Moreau, E.; Chevallier, F.; O'keeffe, U. Multiple-scattering microwave radiative transfer for data assimilation applications. Q. J. R. Meteorol. Soc. 2006, 132, 1259-1281. [CrossRef]

23. Aires, F.; Prigent, C.; Bernardo, F.; Jiménez, C.; Saunders, R.; Brunel, P. A Tool to Estimate Land-Surface Emissivities at Microwave frequencies (TELSEM) for use in numerical weather prediction. Q. J. R. Meteorol. Soc. 2011, 137, 690-699. [CrossRef]

24. de Rosnay, P.; Balsamo, G.; Albergel, C.; Muñoz-Sabater, J.; Isaksen, L. Initialisation of land surface variables for Numerical Weather Prediction. Surv. Geophys. 2014, 35, 607-621. [CrossRef]

25. de Rosnay, P.; Isaksen, L.; Dahoui, L. Snow Data Assimilation at ECMWF; ECMWF Newsletter no 143; ECMWF: Reading, UK, 2015; pp. 26-31.

26. Lovel, T.R.; Reed, B.C.; Brown, J.F.; Ohlen, D.O.; Zhu, Z.; Yang, L.W.; Merchant, J.W. Development of a global land cover characteristics database and IGB6Cover from the $1 \mathrm{~km}$ AVHRR data. Int. J. Remote Sens. 2000, 21, 1303-1330.

27. FAO. FAO Digital Soil Map of the World (DSMW); Technical Report of the United Nations; Food and Agriculture Organization: Rome, Italy, 2003.

28. de Rosnay, P.; Drusch, M.; Boone, A.; Balsamo, G.; Decharme, B.; Harris, P.; Kerr, Y.; Pellarin, T.; Polcher, J.; Wigneron, J.P. Microwave Land Surface modelling evaluation against AMSR-E data over West Africa. The AMMA Land Surface Model Intercomparison Experiment coupled to the Community Microwave Emission Model (ALMIP-MEM). J. Geophys. Res. 2009, 114. [CrossRef]

29. Drusch, M.; Holmes, T.; de Rosnay, P.; Balsamo, G. Comparing ERA-40 based L-band brightness temperatures with Skylab observations: A calibration/validation study using the Community Microwave Emission Model. J. Hydrometeorol. 2009. [CrossRef] 
30. Holmes, T.; Drusch, M.; Wigneron, J.P.; de Jeu, R. A global simulation of microwave emission: Error structures based on output from ECMWFs operational Integrated Forecast System. IEEE Trans. Geosci. Remote Sens. 2008, 46, 846-856. [CrossRef]

31. Muñoz-Sabater, J.; de Rosnay, P.; Albergel, C.; Isaksen, L. Sensitivity of soil moisture analyses to contrasting background and observation error scenarios. Water 2018, 10, 890. [CrossRef]

32. Carrera, M.; Bèlair, S.; Bilodeau, B. The Canadian Land Data Assimilation System (CaLDAS): Description and synthetic Evaluation Study. J. Hydrometeorol. 2015, 16, 1293-1314. [CrossRef]

33. Lievens, H.; Al Bitar, A.; Verhoest, N.; Cabot, F.; De Lannoy, G.; Drusch, M.; Dumedah, G.; Hendricks Franssen, H.; Kerr, Y.; Tomer, S.; et al. Optimization of a Radiative Transfer Forward Operator for Simulating SMOS Brightness Temperatures over the Upper Mississippi Basin. J. Hydrometeorol. 2015, 16, 1109-1134. [CrossRef]

34. Dobson, M.; Ulaby, F.; Hallikainen, M.; EL-Rayes, M. Microwave dielectric behavior of wet soil-Part II: Dielectric mixing models. IEEE Trans. Geosci. Sci. 1985, 38, 1635-1643. [CrossRef]

35. Mironov, V.; Dobson, M.; Kaupp, V.; Komarov, S.; Kleshchenko, V. Generalized refractive mixing dielectric model for moist soils. IEEE Trans. Geosci. Remote Sens. 2004, 42, 773-785. [CrossRef]

36. Wang, J.R.; Schmugge, T. An empirical model for the complex dielectric permittivity of soils as a function of water content. IEEE Trans. Geosci. Remote Sens. 1980, 18, 288-295. [CrossRef]

37. Mironov, V.; Fomin, S. Temperature and mineralogy ependable model for microwave dielectric spectra of moist soils. PIERS Online 2009, 5, 411-415. [CrossRef]

38. Calvet, J.C.; Wigneron, J.P.; Chanzy, A.; Suresh Raju, C.P.; Laguerre, L. Microwave dielectric properties of a silt-Loam at high frequencies. IEEE Trans. Geosci. Remote Sens. 1995, 33, 634-642. [CrossRef]

39. Grody, N.; Weng, F. Microwave emission and scattering from deserts: Theory compared with satellite measurements. IEEE Trans. Geosci. Remote Sens. 2008, 46, 361-375. [CrossRef]

40. Lange, M.; de Rosnay, P. Evaluation of a microwave emissivity module for desert regions with CMEM. Earth Space Sci. 2019, 6, 1787-1795. [CrossRef]

41. Choudhury, B.; Schmugge, T.; Mo, T. A parameterization of effective soil temperature for microwave emission. J. Geophys. Res. 1982, 87, 1301-1304. [CrossRef]

42. Holmes, T.; de Rosnay, P.; de Jeu, R.; Wigneron, J.P.; Kerr, Y.H.; Calvet, J.C.; Escorihuela, M.J.; Saleh, K.; Lemaître, F. A new parameterization of the Effective Temperature for L-band Radiometry. Geophy. Res. Lett. 2006, 33, L07405. [CrossRef]

43. Wigneron, J.P.; Laguerre, L.; Kerr, Y.H. A Simple Parmeterization of the L-band Microwave Emission from Rough Agricultural Soils. IEEE Trans. Geosci. Remote Sens. 2001, 39, 1697-1707. [CrossRef]

44. Wegmüller, U.; Mätzler, C. Rough bare soil reflectivity model. IEEE Trans. Geosci. Electron. 1999, 37, 1391-1395. [CrossRef]

45. Choudhury, B.; Schmugge, T.; Chang, A.; Newton, R. Effect of surface roughness on the microwave emission from soils. J. Geophys. Res. 1979, 84, 5699-5706. [CrossRef]

46. Kerr, Y.; Waldteufel, P.; Richaume, P.; Davenport, I.; Ferrazzoli, P.; Wigneron, J.P. Algorithm Theoretical Based Document (ATBD) for the SMOS Level 2 Soil Moisture Processor Development Continuation; SO-TN-ARR-L2PP-0037, issue 3.4; Array Systems Computing Inc.: Toronto, ON, Canada, 2010.

47. Wigneron, J.P.; Kerr, Y.H.; Waldteufel, P.; Saleh, K.; Escorihuela, M.J.; Richaume, P.; Ferrazzoli, P.; de Rosnay, P.; Gurney, R.; Calvet, J.C.; et al. L-band Microwave Emission of the Biosphere (L-MEB) Model: Description and calibration against experimental data sets over crop fields. Remote Sens. Environ. 2007, 107, 639-655. [CrossRef]

48. Wang, S.; Wigneron, J.P.; Jiang, L.M.; Parrens, M.; Yu, X.Y.; Al-Yaari, A.; Ye, Q.Y.; Fernandez-Moran, R.; Ji, W.; Kerr, Y. Global-Scale evaluation of roughness effects on C-band AMSR-E observations. Remote Sens. 2015, 7, 5734-5757. [CrossRef]

49. Wegmüller, U.; Mätzler, C.; Njoku, E. Canopy Opacity Models, in Passive Microwave Remote Sensing of Land-Atmosphere Interactions; Choudhury, B.J., Pampaloni, P., Eds.; VSP: Utrecht, The Netherlands, 1995; p. 375.

50. Jackson, T.; O'Neill, P. Attenuation of soil microwave emission by corn and soybeans at 1.4 and $5 \mathrm{GHz}$. IEEE Trans. Geosci. Remote Sens. 1990, 28, 978-980. [CrossRef]

51. Kirdyashev, K.; Chukhlantsev, A.; Shutko, A. Microwave radiation of the earths surface in the presence of vegetation cover. Radiotekhnika I Elektron. 1979, 24, 256-264. 
52. Mätzler, C. Microwave (1-100 GHz) dielectric model of leaves. IEEE Trans. Geosci. Remote Sens. 1994, 32, 947-949. [CrossRef]

53. Kou, X.; Chai, L.; Jiang, L.; Zhao, S.; Yan, S. Modeling of the permittivity of holly leaves in frozen environments. IEEE Trans. Geosci. Remote Sens. 2015, 53, 6048-6057. [CrossRef]

54. Lemmetyinen, J.; Pulliainen, J.; Rees, A.; Kontu, A.; Qiu, Y.; Derksen, C. Multiple-Layer adaptation of HUT snow emission model: Comparison with experimental data. IEEE Trans. Geosci. Remote Sens. 2010, 48, 2781-2794. [CrossRef]

55. Anderson, E.A. A Point Energy and Mass Balance Model of a Snow Cover (NWS 19); National Oceanic and Atmospheric Administration (NOAA): Silver Spring, MD, USA, 1976.

56. Pellarin, T.; Wigneron, J.P.; Calvet, J.C.; Berger, M.; Douville, H.; Ferrazzoli, P.; Kerr, Y.H.; Lopez-Baeza, E.; Pulliainen, J.; Simmonds, L.; et al. Two-year global simulation of L-band brightness temperature over land. IEEE Trans. Geosci. Remote Sens. 2003, 41, 2135-2139. [CrossRef]

57. Ulaby, F.; Moore, R.; Fung, A. Microwave Remote Sensing: Active and Passive, Vol I, Microwave Remote Sensing Fundamentals and Radiometry; Addison-Wesley Publishing: Boston, MA, USA, 1981.

58. Wigneron, J.P.; Chanzy, A.; Calvet, J.C.; Bruguier, N. A simple algorithm to retrieve soil moisture and vegetation biomass using passive microwave measurements over crop fields. Remote Sens. Environ. 1995, 51, 331-341. [CrossRef]

59. Boone, A. Description du Schema de Neige ISBA-ES (Explicit Snow); CNRM: Meteo, France, 2002.

60. Hersbach, H.; Bell, B.; Berrisford, P.; Hirahara, S.; Horanyi, A.; Muñoz-Sabater, J.; Nicolas, J.; Peubey, C.; Radu, R.; Schepers, D.; et al. The ERA5 Global Reanalysis. Q. J. R. Meteorol. Soc. 2020. [CrossRef]

61. Newton, R.; Rouse, J. Microwave radiometer measurements of soil moisture content. IEEE Trans. Antennas Propag. 1980, 28, 680-686. [CrossRef]

62. Shi, X.; Sturm, M.; Liston, G.E.; Jordan, R.E.; Lettenmaier, D.P. SnowSTAR2002 Transect Reconstruction Using a Multilayered Energy and Mass Balance Snow Model. J. Hydrometeorol. 2009, 10, 1151-1167. [CrossRef]

(C) 2020 by the authors. Licensee MDPI, Basel, Switzerland. This article is an open access article distributed under the terms and conditions of the Creative Commons Attribution (CC BY) license (http:/ / creativecommons.org/licenses/by/4.0/). 